\title{
Exploring Multiple Potential Energy Surfaces: Photochemistry of Small Carbonyl Compounds
}

\author{
Satoshi Maeda, ${ }^{1,2}$ Koichi Ohno, ${ }^{3}$ and Keiji Morokuma ${ }^{2,4}$ \\ ${ }^{1}$ The Hakubi Center, Kyoto University, Kyoto 606-8302, Japan \\ ${ }^{2}$ Fukui Institute for Fundamental Chemistry, Kyoto University, Kyoto 606-8103, Japan \\ ${ }^{3}$ Toyota Physical and Chemical Research Institute, Nagakute, Aichi 480-1192, Japan \\ ${ }^{4}$ Department of Chemistry and The Cherry L. Emerson Center for Scientific Computation, Emory University, \\ Atlanta, GA 30322, USA
}

Correspondence should be addressed to Satoshi Maeda, smaeda@fukui.kyoto-u.ac.jp and Keiji Morokuma, keiji.morokuma@emory.edu

Received 20 June 2011; Accepted 9 August 2011

Academic Editor: Xinchuan Huang

Copyright (c) 2012 Satoshi Maeda et al. This is an open access article distributed under the Creative Commons Attribution License, which permits unrestricted use, distribution, and reproduction in any medium, provided the original work is properly cited.

\begin{abstract}
In theoretical studies of chemical reactions involving multiple potential energy surfaces (PESs) such as photochemical reactions, seams of intersection among the PESs often complicate the analysis. In this paper, we review our recipe for exploring multiple PESs by using an automated reaction path search method which has previously been applied to single PESs. Although any such methods for single PESs can be employed in the recipe, the global reaction route mapping (GRRM) method was employed in this study. By combining GRRM with the proposed recipe, all critical regions, that is, transition states, conical intersections, intersection seams, and local minima, associated with multiple PESs, can be explored automatically. As illustrative examples, applications to photochemistry of formaldehyde and acetone are described. In these examples as well as in recent applications to other systems, the present approach led to discovery of many unexpected nonadiabatic pathways, by which some complicated experimental data have been explained very clearly.
\end{abstract}

\section{Introduction}

In order to theoretically unravel the entire photochemical reaction processes of a given system, one has to explore and characterize systematically several excited as well as the ground state potential energy surfaces (PESs). In the FranckCondon (FC) approximation, a reaction starts from the FC point on an excited state PES. Then, the system undergoes either adiabatic or nonadiabatic pathways depending on a given excess energy and topographies on the PESs. In adiabatic paths, a bond reorganization occurs directly on the excited state PES through transition states (TSs). In nonadiabatic paths, on the other hand, the system makes nonadiabatic transition to a lower PES and then reacts on the lower PES. The system may cascade through several PESs via nonadiabatic transitions. Seams of intersection between two PESs often play a key role in various reactions [1-7]; near an intersection seam, nonadiabatic transitions can take place efficiently. When the two states have the same spin and space symmetry, the intersection hyperspace consists of $f-2$ dimensions and is called "conical intersection (CI)," where $f$ is the number of vibrational degrees of freedom. If the spin multiplicity and/or the space symmetry are different, the PESs cross simply in $f-1$ dimensional hyperspace. In this paper, both of these two types of intersections, that is, conical intersection and simple intersection seam, are denoted as "seam-of-crossing." In many kinetic studies, minimum energy structures on seam-of-crossing hyperspaces (MSXs) have been searched as critical points of nonadiabatic transitions. In short, to find all possible photochemical reaction pathways of a given system, systematic search for TSs and MSXs is required for all PESs below a given photon energy.

There have been considerable efforts on development of geometry optimization methods for MSXs [8-16] as well as for TSs [17-26]. A variety of geometry optimization 
techniques, such as the gradient minimization $[17,18]$, the Berny optimization $[19,20]$, the eigenvector following [21], the geometry direct inversion in the iterative subspace [22], and the rational function optimization [23], have been a great help to locate the exact saddle point starting from a guessed TS structure. MSX optimization methods can be classified into three types: constrained optimization methods [8-10], the direct gradient (DG) method [11, 12], and penalty function (PF) methods $[13,14]$. These methods were compared systematically, and the former two were shown to converge more quickly than a PF method [15]. On the other hand, PF methods have a significant advantage that nonadiabatic coupling derivative vector (CDV) calculations are not required in optimization of MSXs of the conical intersection type. Recently, CDV calculations can be avoided even in constrained optimization methods and in the DG method by using the branching plane updating method [16]. These methods have been successfully applied to many theoretical analyses of photochemical reactions.

In general, geometry optimization requires a good initial guess. However, guesses of MSX structures are sometimes very difficult, because their shapes are often highly deviated from those of stable molecular structures. A similar problem sometimes arises also in the search for TSs on a single PES. To avoid this problem, many automated TS (or minimum energy path) search methods have been developed [2742]. Although most of these require guesses of a reaction mechanism such as key structures (product and intermediates) [27-34] or chemically relevant collective variables [35-37], some (relatively expensive) methods do not use any guess [38-42]. We also have developed two unique methods without needing any guess: the global reaction route mapping (GRRM) [43-45] method and the artificial force-induced reaction (AFIR) [46-48] method. GRRM can execute global mapping of reaction path networks of unimolecular isomerizations and dissociations on PESs of given atomic composition. AFIR can efficiently explore associative reaction paths among given reactants of multicomponent reactions. Although application of these automatic TS search methods to excited state PESs seems to be straightforward, it had not been successful probably because there are singular points in low-energy regions of excited state PESs due to conical intersections as discussed in Section 2.1. There has been no practical method for the automated MSX search either.

In this paper, we describe a recipe for exploring multiple PESs automatically. Two model functions, $F^{\mathrm{AMF}}$ and $F^{\mathrm{SMF}}$ $[49,50]$, are introduced for the TS search and the MSX search, respectively, in combination with the GRRM method. Although, in this study, it is applied to photochemical reactions, it can be applied to other nonadiabatic reactions such as ion-molecule reactions, organometallic reactions, and combustion reactions. Furthermore, the present recipe can adopt, instead of GRRM, any automated reaction path search method such as AFIR. In the present paper, we apply the proposed recipe with the GRRM method to photodissociation mechanisms of small carbonyl compounds such as formaldehyde $\mathrm{H}_{2} \mathrm{CO}$ and acetone $\left(\mathrm{CH}_{3}\right)_{2} \mathrm{CO}[49,51]$.

\section{Theory}

2.1. Avoiding Model Function (AMF) Approach. Figure 1(a) schematically illustrates a one-dimensional cut of two coupled adiabatic PESs. Along the curve for the upper PES, there is a local minimum in the left-hand side and a conical intersection in the right-hand side. In the conical intersection, the adiabatic PES is singular due to the coupling between two diabatic surfaces. To eliminate the singular point from the adiabatic PES, we use the following avoiding model function in automated search:

$$
\begin{aligned}
F^{\mathrm{AMF}}(\mathbf{Q})= & \frac{1}{2}\left(E^{\text {State } 1}(\mathbf{Q})+E^{\text {State } 2}(\mathbf{Q})\right) \\
& +\frac{1}{2} \sqrt{\left(E^{\text {State } 1}(\mathbf{Q})-E^{\text {State } 2}(\mathbf{Q})\right)^{2}+4 U^{2}}, \\
U(\mathbf{Q})= & \frac{\alpha}{2} \exp \left[-\left(\frac{E^{\text {State } 1}(\mathbf{Q})-E^{\text {State } 2}(\mathbf{Q})}{\alpha}\right)^{2}\right],
\end{aligned}
$$

where $\mathbf{Q}$ is the atomic coordinates $\left\{Q_{i}\right\}, E^{\text {State } 1}(\mathbf{Q})$ is an adiabatic PES of the target (upper) state, $E^{\text {State } 2}(\mathbf{Q})$ is an adiabatic PES of the lower state, and $\alpha$ is a constant parameter. This $F^{\mathrm{AMF}}$ is very similar to the well-known equation for the diabatic/adiabatic transformation for two state systems, where $E^{\text {State } n}$ should be diabatic energies in the equation. In this study, adiabatic energies were substituted for $E^{\text {State } n}$. As seen in Figure 1(b), the model coupling function $U$ in (1) changes the conical intersection region to an avoided crossing-like smooth curve. Thus, any automated search methods that require a smooth PES can be applied to $F^{\mathrm{AMF}}$. TSs on $F^{\mathrm{AMF}}$ may be meaningless if the difference between $F^{\mathrm{AMF}}$ and $E^{\text {State } 1}$ is significant in TS regions, and therefore $U$ was designed to have effects only in limited regions with a small energy gap. Hence, in TS regions $F^{\mathrm{AMF}}$ is often very similar to $E^{\text {State } 1}$. The accuracy (how well TSs on $F^{\mathrm{AMF}}$ reproduce TSs on $E^{\text {State } 1}$ ) depends on the value of $\alpha$. To our experience, $\alpha$ should be about $1 / 10$ of the vertical excitation energy of target reactions. In this study, we use $\alpha=30 \mathrm{~kJ} / \mathrm{mol}$ throughout.

An example is shown in Figure 1(c) for the direct dissociation channel of $\mathrm{H}_{2} \mathrm{CO}$ on the $\mathrm{S}_{1}$ PES. Starting from $\mathrm{S}_{1}$ TS, the backward IRC (intrinsic reaction coordinate) reaches $\mathrm{S}_{1}$-MIN, while the forward IRC crosses $\mathrm{S}_{0} / \mathrm{S}_{1}$-MSX (conical intersection) in a partially dissociated region. Behind these (true) critical structures, local minima and a saddle point on $F^{\mathrm{AMF}}$ (with $\alpha=30 \mathrm{~kJ} / \mathrm{mol}$ ) are shown in black. As seen in Figure 1(c), the saddle point structure on $F^{\mathrm{AMF}}$ perfectly overlaps with $S_{1}$-TS (identical within convergence criteria of geometry optimization: maximum absolute gradient $g_{\mathrm{MAX}}=$ $6.0 \times 10^{-5}$ hartree $\AA^{-1}$, root mean square gradient $g_{\mathrm{RMS}}=$ $4.0 \times 10^{-5}$ hartree $\AA^{-1}$, maximum absolute displacement $d_{\mathrm{MAX}}=3.0 \times 10^{-4} \AA$, root mean square displacement $d_{\mathrm{RMS}}=$ $2.0 \times 10^{-4} \AA$ ). $\mathrm{S}_{1}$-MIN is also reproduced perfectly by the minimum on $F^{\mathrm{AMF}}$. Moreover, on $F^{\mathrm{AMF}}, \mathrm{S}_{0} / \mathrm{S}_{1}$-MSX turned into a local minimum shown in black behind $\mathrm{S}_{0} / \mathrm{S}_{1}-\mathrm{MSX}$. In other words, the conical intersection does not exist on $F^{\mathrm{AMF}}$, which enables exploring the smooth $F^{\mathrm{AMF}}$ with an automated reaction path search method. 


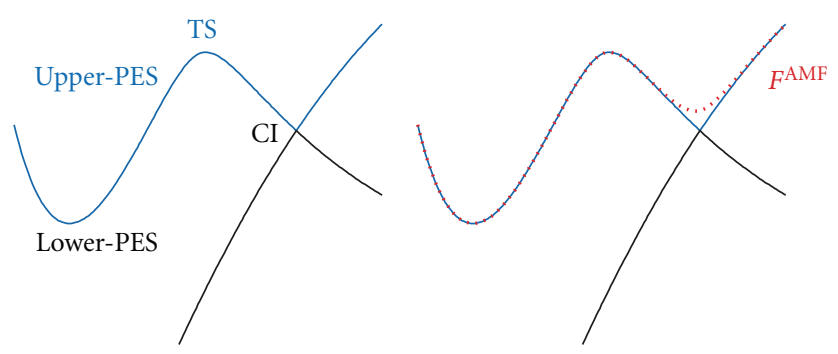

(a)

(b)
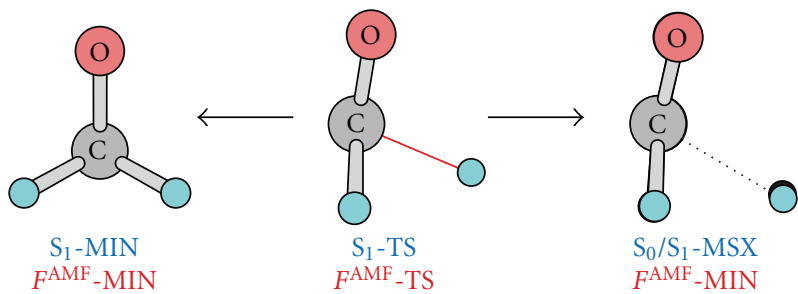

(c)

Figure 1: (a) A schematic one-dimensional curve of two coupled adiabatic PESs, (b) an example of $F^{\mathrm{AMF}}$ for the PESs in (a), and (c) comparisons between stationary points on $F^{\mathrm{AMF}}$ (with $\alpha=$ $30 \mathrm{~kJ} / \mathrm{mol}$ ) and those on the $\mathrm{S}_{1}$-PES of $\mathrm{H}_{2} \mathrm{CO}$ (see Section 2.4 for the ab initio calculation level). Each structure shown in (c) corresponds to $\mathrm{S}_{1}$-MIN, $\mathrm{S}_{1}$-TS, and $\mathrm{S}_{0} / \mathrm{S}_{1}$-MSX (conical intersection), respectively, and stationary structures on $F^{\mathrm{AMF}}$ are overlapped in black behind them. At $\mathrm{S}_{1}$-MIN and $\mathrm{S}_{1}$-TS, the stationary structures on $F^{\mathrm{AMF}}$ are identical to them within the convergence criteria (see text) of geometry optimization and cannot be seen. $F^{\mathrm{AMF}}-\mathrm{MIN}$ can barely be seen behind $\mathrm{S}_{0} / \mathrm{S}_{1}$-MSX.

In short, TSs on an excited state (adiabatic) PES $E^{\text {State } 1}$ can be explored in two steps: a search for many TS-like structures as first-order saddles on $F^{\mathrm{AMF}}$ by an automated search method, optimization of true TSs on the PES $E^{\text {State } 1}$ using the TS-like structures as initial guesses. It should be noted that all TSs shown below are fully optimized first-order saddle points (true TSs) on adiabatic PESs.

2.2. Seam Model Function (SMF) Approach. In the automated search for MSXs, the following model function $F^{\text {SMF }}$ is considered $[49,50]$ :

$$
\begin{aligned}
F^{\mathrm{SMF}}(\mathbf{Q})= & \frac{1}{2}\left(E^{\text {State } 1}(\mathbf{Q})+E^{\text {State } 2}(\mathbf{Q})\right) \\
& +\frac{\left(E^{\text {State } 1}(\mathbf{Q})-E^{\text {State } 2}(\mathbf{Q})\right)^{2}}{\beta},
\end{aligned}
$$

where $\mathbf{Q}$ is the atomic coordinates $\left\{Q_{i}\right\}, E^{\text {State } 1}(\mathbf{Q})$ and $E^{\text {State } 2}(\mathbf{Q})$ are PESs of two target states, and $\beta$ is a constant parameter. Minimization of $F^{\mathrm{SMF}}$ gives a geometry in which both the mean energy of the two states (the first term) and the energy gap between the two states (the second term) are small. Hence, minima on $F^{\mathrm{SMF}}$ can be good guesses of MSXs. Equation (2), which is also called penalty function (PF), or more complicated PFs have been employed in MSX geometry optimization $[13,14]$. As discussed above, PF methods have a drawback concerned with convergence in MSX optimization
[15]. However, in automated searches, use of the PF has a significant advantage that the PF is a single smooth function, which permits the application of automated search methods developed for single PESs without any modification. Hence, we proposed the SMF approach which consists of two steps: (a) a search for many MSX-like structures as local minima on the PF using an automated search method and (b) determination of (true) MSX structures by using one of MSX optimization methods and MSX-like structures obtained in (a) as initial guesses.

Although smaller $\beta$ gives better (more accurate) candidates, minimizations of $F^{\mathrm{SMF}}$ with smaller $\beta$ need more optimization steps since at $\beta=0$ the function becomes singular. This is the cause of the slow convergence of a PF method observed in the systematic comparative study. To avoid this, use of relatively large $\beta$ (typically $\beta \sim 30-$ $50 \mathrm{~kJ} / \mathrm{mol}$ ) is recommended since the purpose of the first step (a) is to systematically collect many MSX-like structures as quick as possible. In this study, we use $\beta=30 \mathrm{~kJ} / \mathrm{mol}$ throughout. It should be noted that all MSXs shown below are fully optimized true MSXs (the energy gap between two target states is smaller than $0.1 \mathrm{~kJ} / \mathrm{mol}$ in all MSXs).

2.3. Global Reaction Route Mapping (GRRM) Method. In the GRRM method [43-45], global mapping of reaction path networks is executed by following the path network itself. To make such a search, one has to follow the paths in both uphill (minimum to saddle) and downhill (saddle to minimum) directions. The latter can be accomplished by following the IRC [52] using one of advanced steepest decent path methods [53-57]. The former, that is, uphill walk, had been difficult before 2004 until we proposed the anharmonic downward distortion following (ADDF) approach.

Many typical potential curves show a common feature that potential energy always become lower than the harmonic potential defined at the bottom of the curves in directions leading to TSs. Thus, reaction channels can be found by following ADD maxima starting from a local minimum on a PES. In many previous applications, the GRRM method based on the ADDF approach has found many unknown as well as nearly all known reaction channels automatically. The ADD maxima can be detected in multidimension by using the scaled hypersphere search (SHS) technique. Details of the SHS technique can be found in our previous papers [43-45].

Following all ADDs starting from all obtained local minima will provide an entire global map on PESs. Such a treatment called full-ADDF, denoted GRRM $(f$-ADDF), is very expensive, and its application is limited to small systems. An approach following only large ADDs, largeADDF denoted GRRM(l-ADDF), is effective to survey lowenergy regions of PESs in large systems [58]. Another useful option for speedup is double-ended ADDF, denoted $\operatorname{GRRM}(d-\mathrm{ADDF})$, which confines the search area between given reactant and product geometries $[33,34]$.

2.4. Computational Methods Used in Applications. In this section, we summarize quantum chemical methods used in the applications in the following sections. For details, see original articles $[49,51]$. 
In an application to $\mathrm{H}_{2} \mathrm{CO}, \mathrm{GRRM}(f-\mathrm{ADDF})$ was applied to $F^{\mathrm{SMF}}$ at the 3SA-CAS(4e,3o)-SCF/6-31G and 3SACAS(2e,3o)-SCF/6-31G levels, where SA stands for stateaverage and the averaged three states are $S_{0}, S_{1}$, and $T_{1}$. All obtained MSX-like structures were fully optimized at the $2 S$ CAS(12e,10o)-PT2/aug-cc-pVDZ level for the singlet states and at the SS-CAS(12e,10o)-PT2/aug-cc-pVDZ level for the triplet state, where $2 \mathrm{~S}$ and SS stand for two-state averaged and single-state, respectively. In the state averaging, equal weights were used. All (known) TSs and local minima on these PESs were optimized at the same (CASPT2) levels.

In an application to $\left(\mathrm{CH}_{3}\right)_{2} \mathrm{CO}, \mathrm{GRRM}(d-\mathrm{ADDF})$ was applied to $F^{\mathrm{SMF}}$ and $F^{\mathrm{AMF}}$ at the 2SA-CAS $(8 \mathrm{e}, 7 \mathrm{o})-\mathrm{SCF} / 6-31 \mathrm{G}$ and SS-CAS(8e,7o)-SCF/6-31G levels for the $\mathrm{S}_{0}, \mathrm{~S}_{1}$, and $\mathrm{T}_{1}$ states, respectively, where SS here stands for state-specific. In addition to $\left(\mathrm{CH}_{3}\right)_{2} \mathrm{CO}$, three isomers, $\mathrm{CH}_{2}=\mathrm{C}(\mathrm{OH})-$ $\mathrm{CH}_{3}$ (enol), ${ }^{\bullet} \mathrm{CH}_{2}-\mathrm{CH}\left(\mathrm{O}^{\bullet}\right)-\mathrm{CH}_{3}$ (biradical), and $\mathrm{CH}_{3}-$ $\mathrm{CO}-\mathrm{CH}_{3}$ (carbene), and a partially dissociated geometry $\mathrm{CH}_{3} \mathrm{CO} \cdots \mathrm{CH}_{3}$ were considered as the end points for $d$ ADDF. All obtained MSX-like structures and TS-like structures were fully optimized at the 2S-CAS(8e,7o)-PT2/6$31+\mathrm{G}^{*}$ level for the singlet states and at the SS-CAS $(8 \mathrm{e}, 7 \mathrm{o})-$ PT2/6-31+G* level for the triplet state. Local minima were optimized also at the same (CASPT2) levels.

Potential energies and gradients required for the searches as well as optimization were computed by the Molpro2006 program [59]. Using these quantities, all geometrical displacements were treated by the GRRM11 program [60].

\section{Photodissociation of Formaldehyde}

It was suggested experimentally that the photodissociation of $\mathrm{H}_{2} \mathrm{CO}$ at low-photon energies occurs on the $\mathrm{S}_{0} \mathrm{PES}$ after an internal conversion (IC) from the $S_{1}$ PES [61-65]. Hence, dynamics as well as stationary points on the ground state $S_{0}$ PES have been studied extensively by theoretical calculations [39, 40, 43-45, 66-89]. The focuses in early studies had been on the following two channels:

$$
\begin{gathered}
\mathrm{H}_{2} \mathrm{CO} \longrightarrow \mathrm{CO}+\mathrm{H}_{2}, \\
\mathrm{H}_{2} \mathrm{CO} \longrightarrow \mathrm{HCO}+\mathrm{H},
\end{gathered}
$$

The TS for the channel (3), which is often called "tightTS," was already determined in 1974 by ab initio calculations [67]. The radical dissociation (4) can occur both from the $\mathrm{S}_{0}$ PES and from the $T_{1}$ PES, and hence the $T_{1}$ PES has also been studied $[90,91]$. Knowledge of the higher singlet states was rather scarce until very recently $[92,93]$. A new channel for the molecular products was experimentally proposed in 1993 [94]; the channel is often represented as

$$
\mathrm{H}_{2} \mathrm{CO} \longrightarrow \mathrm{HCO} \cdots \mathrm{H} \longrightarrow \mathrm{CO}+\mathrm{H}_{2}
$$

where one of $\mathrm{H}$ atoms, once partially dissociated, roams around the $\mathrm{HCO}$ fragment and finally abstracts the other $\mathrm{H}$ atom to generate $\mathrm{CO}+\mathrm{H}_{2}$. This speculation was confirmed in 2004 by combined experimental and theoretical studies [95]. Since its discovery, this channel named "roaming" has been a hot topic as a new type of reaction mechanism [9698], and it has been found in many reactions having implications to atmospheric chemistry [99-108] and combustion chemistry $[88,109,110]$.

The IC was postulated to occur in the potential well of $\mathrm{H}_{2} \mathrm{CO}$ in many previous studies. However, recently, several MSXs were found outside the potential well of $\mathrm{H}_{2} \mathrm{CO}$ : two $\mathrm{S}_{0} / \mathrm{T}_{1}$-MSXs were located in the potential well of hydroxycarbene $\mathrm{HCOH}[111,112], \mathrm{S}_{0} / \mathrm{S}_{1}$-MSX was located in a partially dissociated $\mathrm{H}$. . HCO region [113]. In 2009, we explored multiple PESs for the $S_{0}, S_{1}$, and $T_{1}$ states by the SMF-GRRM approach [49]. The potential energy profile we discovered is presented in Figure 2, where the high-energy regions for $\mathrm{H}_{2} \mathrm{O} \cdots \mathrm{C}$ and $\mathrm{H}_{2} \mathrm{C} \cdots \mathrm{O}$ are not shown. The two $\mathrm{S}_{0} / \mathrm{T}_{1}$-MSXs of $\mathrm{HCOH}[111,112]$ are denoted as $\mathrm{S}_{0} / \mathrm{T}_{1}$ MSX2 and $S_{0} / T_{1}-M S X 3$, and the partially dissociated $S_{0} / S_{1}$ MSX [113] is shown as $S_{0} / S_{1}-M S X 1$. As seen in this figure, to isomerize on the $\mathrm{T}_{1}$ PES or to partially dissociate on the $\mathrm{S}_{1}$ PES, the system has to overcome a significant barrier. At low-photon energies $\left(<32000 \mathrm{~cm}^{-1}=383 \mathrm{~kJ} \mathrm{~mol}^{-1}\right)$, these barriers are not accessible. Hence, these known MSXs are not likely involved in the low-energy photodissociation process.

In addition to known MSXs, some new MSX structures were discovered in the automated search. One of those, $\mathrm{S}_{0} / \mathrm{T}_{1}-\mathrm{MSX} 1$, was discovered in the potential well of $\mathrm{H}_{2} \mathrm{CO}$. Adopting this new $\mathrm{S}_{0} / \mathrm{T}_{1}-\mathrm{MSX} 1$ and known excited state TSs $[111,114]$, we proposed the entire mechanism for the lowenergy photolysis as follows. After the photoexcitation the system oscillates around the $S_{1}$-MIN for a long time since there is no $\mathrm{S}_{0} / \mathrm{S}_{1}-\mathrm{MSX}$ in the potential well and the lowest $\mathrm{S}_{1} / \mathrm{T}_{1}-\mathrm{MSX} 1$ is higher than the photon energies. The $\mathrm{S}_{1} / \mathrm{T}_{1}$ intersystem crossing (ISC) may be able to take place by trickling down from $S_{1}$ to $T_{1}$ at all the geometries, while the molecule in the $S_{1}$ state spends a long time oscillating around $S_{1}$-MIN, because PESs for the $S_{1}$ and $T_{1}$ states are very close and nearly parallel to each other in energy at any place in the basin of $S_{1}$-MIN. Although the probability at each geometry may be small because the spin-orbital coupling between the two states belonging to the same electronic configuration is small, the integrated probability over a long time could be substantial. Once the system comes down to $T_{1}$ from the $S_{1}$-MIN basin region, the $T_{1} / S_{0}$ ISC via the newly found $S_{0} / T_{1}-M S X 1\left(390 \mathrm{~kJ} \mathrm{~mol}^{-1}\right)$ can take place in this $\mathrm{H}_{2} \mathrm{CO}$ basin. This mechanism based on the CASPT2 energetics is consistent with the result obtained by the MRCISD $(\mathrm{Q}) / \mathrm{AV} 5 \mathrm{Z}$ calculations, where relative energy values of the three important barriers, that is, the $S_{1}$ (C-H bond scission) barrier, the $\mathrm{T}_{1}$ barrier, and $\mathrm{S}_{0} / \mathrm{T}_{1}$ MSX1, are 456.4, 413.1 and $397.7 \mathrm{~kJ} / \mathrm{mol}$, respectively, at the $\operatorname{MRCISD}(\mathrm{Q}) / A V 5 Z$ level [114]. After the transition to $\mathrm{S}_{0}$, the dynamics on the $\mathrm{S}_{0}$ PES should start in the $\mathrm{H}_{2} \mathrm{CO}$ basin and propagate via the tight-TS or the roaming pathway to give the $\mathrm{CO}+\mathrm{H}_{2}$ product.

After the proposal of this mechanism, direct CASSCF dynamics studies have been conducted for the molecular dissociation at medium excitation energies $[115,116]$. By these simulations, molecular dissociations involving an ISC or a direct IC in the partially dissociated $\mathrm{H}$. . HCO region were proposed. These paths undergo a $\mathrm{C}-\mathrm{H}$ bond dissociation 


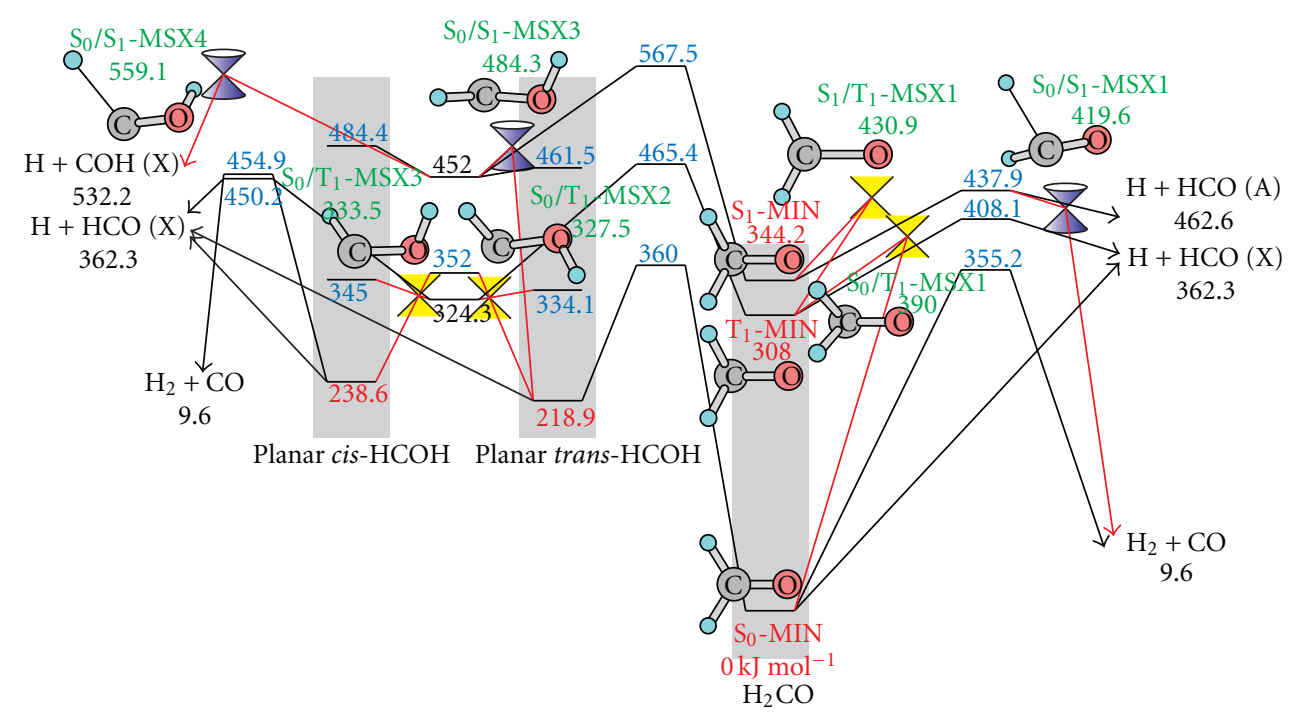

FIGURE 2: A CASPT2 potential energy profile (in $\mathrm{kJ} / \mathrm{mol}$ ) for the three low lying $\mathrm{S}_{0}, \mathrm{~S}_{1}$, and $\mathrm{T}_{1}$ states of $\mathrm{H}_{2} \mathrm{CO}$ [49]. Reprinted with permission from [49]. Copyright 2009 American Chemical Society.

on either the $T_{1}$ or $S_{1}$ PESs. Obviously, the $S_{1}$ dissociation needs sufficient (medium) photon energies to overcome the $S_{1}$ barrier. The other path involving the partial dissociation on the $T_{1}$ PES may happen via tunneling or zero-pointenergy effect even at the low photon energies. However, this (molecular dissociation involving the $\mathrm{T}_{1}$ dissociation) was shown to be a very minor process in recent three-state trajectory surface hopping (3S-TSH) simulations including the $\mathrm{S}_{0}, \mathrm{~S}_{1}$, and $\mathrm{T}_{1}$ states [117]. In the 3S-TSH simulations, highly accurate (analytically fitted) PESs were employed and the hopping was treated by Tully's fewest switches algorithm. The 3S-TSH simulations demonstrated that the above decay mechanism involving the $S_{1}-T_{1}$ trickling down mechanism followed by the $\mathrm{T}_{1}-\mathrm{S}_{0}$ ISC through $\mathrm{S}_{0} / \mathrm{T}_{1}$-MSX1 in the potential well of $\mathrm{H}_{2} \mathrm{CO}$ is the major process before the molecular dissociation. Furthermore, they discovered a new unexpected (but minor) dynamics in which the system once decays down to the $\mathrm{S}_{0}$ PES and then isomerize to $\mathrm{HCOH}$ on the $S_{0}$ PES before the dissociation. Surprisingly, in such trajectories, the system hops up to the $\mathrm{T}_{1}$ PES and then hops down to the $\mathrm{S}_{0}$ PES through $\mathrm{S}_{0} / \mathrm{T}_{1}$-MSX1 or $\mathrm{S}_{0} / \mathrm{T}_{1}$-MSX2. This is energetically certainly allowed in Figure 2.

\section{Photodissociation of Acetone}

Another example is an application to $\left(\mathrm{CH}_{3}\right)_{2} \mathrm{CO}$ [51]. Photolysis of acetone is one of the most extensively studied photochemical reactions [118]. The CC bond dissociation, called "Norrish type I reaction" $\left(\mathrm{CH}_{3}\right)_{2} \mathrm{CO} \rightarrow \mathrm{CH}_{3} \mathrm{CO}+$ $\mathrm{CH}_{3}$, has been the main focus of many theoretical and experimental studies [119-133]. Roaming was also suggested experimentally [102], which was proposed to proceed on the $\mathrm{S}_{0}$ PES as $\left(\mathrm{CH}_{3}\right)_{2} \mathrm{CO} \rightarrow \mathrm{CH}_{3} \mathrm{CO} \cdots \mathrm{CH}_{3} \rightarrow \mathrm{CO}+\mathrm{CH}_{3}-$ $\mathrm{CH}_{3}$.

In early experimental studies [119-121], it was proposed that the Norrish type I dissociation occurs on the $\mathrm{T}_{1}$ PES (the $T_{1}$ path) after an ISC from the $S_{1}$ PES, as long as the photon energy exceeds the barrier of the CC bond breaking on the $\mathrm{T}_{1}$ PES. A theoretical calculation at the CASSCF level indicated that the ISC happens around a $S_{1} / T_{1}$-MSX structure located below the $T_{1}$ barrier, and the $T_{1}$ path was suggested to be the most preferable channel (at least in terms of potential energy) [122]. However, in later combined femtosecond laser experimental and theoretical studies [123125], it was suggested that the dissociation occurs through the $S_{1}$ barrier (the $S_{1}$ path) before the ISC takes place when photon energies are larger than the $S_{1}$ barrier. The $S_{1}$ path was then confirmed by another femtosecond laser study at $195 \mathrm{~nm}(613 \mathrm{~kJ} / \mathrm{mol})$ [126-128]. Relevant stationary structures for the $S_{1}$ path were examined by CASPT2 and MRCISD(Q) calculations [132]. We revisited [51] the PESs of $\left(\mathrm{CH}_{3}\right)_{2} \mathrm{CO}$ for two purposes: to find nonadiabatic paths to the $\mathrm{S}_{0}$ PES systematically for the roaming channel and to explain the conflict between the fast $\mathrm{S}_{1} / \mathrm{T}_{1}$ ISC proposed by CASSCF calculations and the experimentally observed $S_{1}$ path which overcomes the $S_{1}$ barrier much higher than the CASSCF $S_{1} / T_{1}$-MSX.

Figure 3 presents a potential energy profile for the three low lying $S_{0}, S_{1}$, and $T_{1}$ states. For isomerizations on the $S_{1}$ and $\mathrm{T}_{1}$ PESs, only the lowest channels for the $\left(\mathrm{CH}_{3}\right)_{2} \mathrm{CO} \leftrightarrow$ $\mathrm{CH}_{2}=\mathrm{C}(\mathrm{OH})-\mathrm{CH}_{3}$ reaction $\left(\mathrm{S}_{1}-\mathrm{TS} 2\right.$ and $\left.\mathrm{T}_{1}-\mathrm{TS} 2\right)$ are shown in the profile. As seen in this figure, these excited state isomerizations have higher barriers and must be minor channels compared to the CC bond dissociations $\left(\mathrm{S}_{1}-\mathrm{TS} 1\right.$ and $\mathrm{T}_{1}$ TS1). We should note that the $S_{1} / T_{1}$-MSX is much higher in energy than $\mathrm{T}_{1}$-TS1 on the CASPT2 PESs in contrast to the case of the CASSCF calculations reported previously. Hence, if photon energy is higher than the $S_{1}$ barrier $\left(S_{1}-\mathrm{TS} 1\right)$, the most favorable path is the direct dissociation. This explains the recent femtosecond laser experimental observation very well. Below the $S_{1}$ barrier, there is no exit channel from the $S_{1}$ PES. Hence and also because of very small spin-orbit 


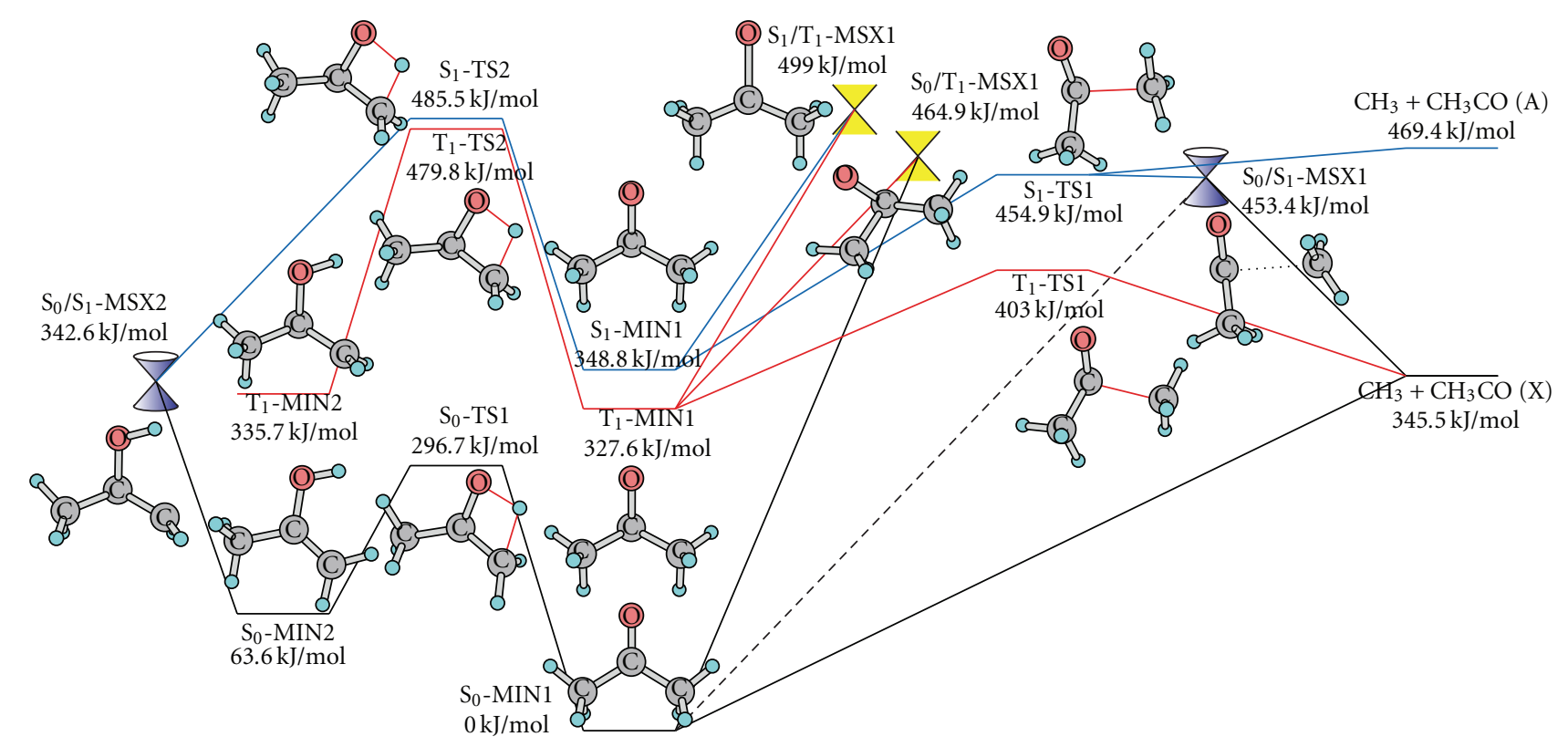

FIgURE 3: A CASPT2 potential profile for the three low lying states $\left(\mathrm{S}_{0}, \mathrm{~S}_{1}\right.$, and $\left.\mathrm{T}_{1}\right)$ of $\left(\mathrm{CH}_{3}\right)_{2} \mathrm{CO}$ [51]. Reprinted with permission from [51]. Copyright 2010 American Chemical Society.

coupling between the $S_{1}$ and $T_{1}$ states, we proposed that the ISC occurs very slowly by trickling down from $S_{1}$ to $T_{1}$ while the molecule in the $S_{1}$ state spends a long time oscillating around $S_{1}-$ MIN1. This may be able to happen because PESs for the $S_{1}$ and $T_{1}$ states are very close and nearly parallel to each other in energy at any place in the basin of $S_{1}$-MIN1, similarly to the case of $\mathrm{H}_{2} \mathrm{CO}$. There are some experimental evidences showing that the $S_{1} / T_{1}$ ISC is very slow [134]; recent time-resolved mass spectrometry and photoelectron spectroscopy experiments and direct dynamics simulations suggested that the system decays from the FC region to the $\mathrm{S}_{1}$ minimum within 30 femtoseconds and then stays on the $\mathrm{S}_{1}$ PES more than 100 picoseconds at $253-288 \mathrm{~nm}(473-$ $415 \mathrm{~kJ} / \mathrm{mol}$ ) excitations $[135,136]$. After coming down to the $\mathrm{T}_{1}$ PES, the system can overcome the $\mathrm{T}_{1}$ barrier to undergo the Norrish type I reaction.

In Figure 3, several decay paths can be found from the $\mathrm{S}_{1}$ PES to the $\mathrm{S}_{0}$ PES. Unlike $\mathrm{H}_{2} \mathrm{CO}, \mathrm{S}_{0} / \mathrm{T}_{1}$-MSX1 in the potential well of $\left(\mathrm{CH}_{3}\right)_{2} \mathrm{CO}$ is much higher in energy than $\mathrm{T}_{1}$-TS1. The lowest path to the $\mathrm{S}_{0}$ PES undergoes a dissociation on the $S_{1}$ PES through $S_{1}$-TS1 followed by a nonadiabatic transition in the nearly dissociated geometry through $S_{0} / S_{1}$-MSX1 and a recombination on the $S_{0}$ PES. The roaming dynamics was observed at $230 \mathrm{~nm}(520 \mathrm{~kJ} / \mathrm{mol})$ [102], at which the direct CC bond dissociation on the $S_{1}$ PES is the dominant path of the Norrish type I reaction. Hence, this is the most likely path to produce the ground state $\left(\mathrm{CH}_{3}\right)_{2} \mathrm{CO}$. At this photon energy, the excited state isomerization to the enol species followed by an IC through $\mathrm{S}_{0} / \mathrm{S}_{1}$-MSX2 and an enol-keto isomerization on the $\mathrm{S}_{0}$ PES may be a minor channel to the ground state $\left(\mathrm{CH}_{3}\right)_{2} \mathrm{CO}$ before the roaming dynamics may take place.

\section{5. $S_{0} / T_{1}$ Intersection Space}

One can find candidates of saddle points on seam-of-crossing hyperspaces (SPSXs) as saddles on $F^{\mathrm{SMF}}$. Minimum energy paths on seam-of-crossing hyperspaces (MEPSXs) starting from SPSXs were suggested to be useful for understanding dynamical trajectories crossing a high-energy region of a seam-of-crossing hyperspace [12]. In this section, SPSXs and MEPSXs for the $S_{0} / T_{1}$ intersection spaces of $\mathrm{H}_{2} \mathrm{CO}$ and $\left(\mathrm{CH}_{3}\right)_{2} \mathrm{CO}$ are discussed because of their significance in the generation of the $S_{0}$ species. The optimization method for SPSXs from SMF (or guessed) structures and an algorithm to calculate an MEPSX from a SPSX are described in our previous paper [16].

Figure 4(a) shows a MEPSX for the $\mathrm{S}_{0} / \mathrm{T}_{1}$ intersection space of $\mathrm{H}_{2} \mathrm{CO}$ at the CASPT2 level. The MEPSX was calculated from two SPSXs. Along the MEPSX, all points have the $\mathrm{S}_{0} / \mathrm{T}_{1}$ energy gap less than $1.0 \mathrm{~kJ} / \mathrm{mol}$. As seen in this figure, the $\mathrm{S}_{0} / \mathrm{T}_{1}$ intersection space was found to be connected from the $\mathrm{HCOH}$ area through the $\mathrm{S}_{0} / \mathrm{T}_{1}-\mathrm{MSX} 1$ geometry to the partially dissociated region. It follows that the $\mathrm{S}_{0} / \mathrm{T}_{1}$ ISC may take place not only at $S_{0} / T_{1}$-MSX1 but also with variety of geometries in this very wide intersection space.

Integration of an MEPSX with CASPT2 is expensive, and we also tested and used the UB3LYP method using Gaussian09 program [137]. At first, the MEPSX for $\mathrm{H}_{2} \mathrm{CO}$ by the UB3LYP method is shown in Figure 4(b). For $\mathrm{H}_{2} \mathrm{CO}$ the MEPSX by UB3LYP is similar to the one by the CASPT2 method. Therefore, we adopted the UB3LYP method for $\left(\mathrm{CH}_{3}\right)_{2} \mathrm{CO}$. Figure 5 shows two MEPSXs (a) for $\mathrm{H}_{2} \mathrm{C}=\mathrm{C}(\mathrm{OH}) \mathrm{CH}_{3} \leftrightarrow\left(\mathrm{CH}_{3}\right)_{2} \mathrm{CO} \leftrightarrow \mathrm{CH}_{3} \mathrm{CO}+\mathrm{CH}_{3}$ and (b) for $\mathrm{CH}_{3}-\mathrm{CO}-\mathrm{CH}_{3} \leftrightarrow\left(\mathrm{CH}_{3}\right)_{2} \mathrm{CO} \leftrightarrow \mathrm{CH}_{3} \mathrm{CO}+\mathrm{CH}_{3}$. Another MEPSX from an MSX of the ${ }^{\bullet} \mathrm{CH}_{2}-\mathrm{CH}\left(\mathrm{O}^{\bullet}\right)-\mathrm{CH}_{3}$ form (not shown) is directly connected to the partially dissociated 


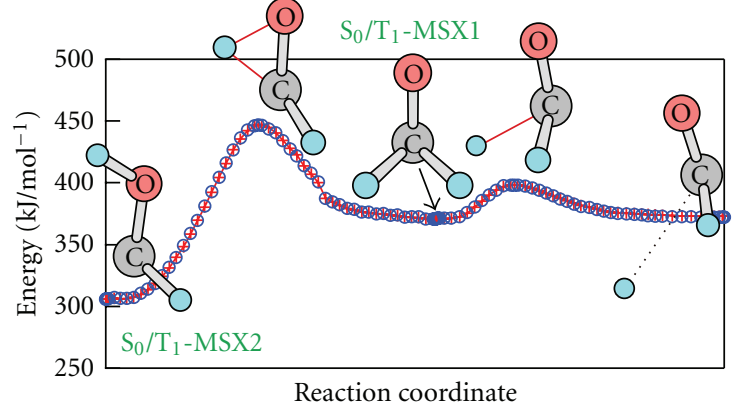

(a)

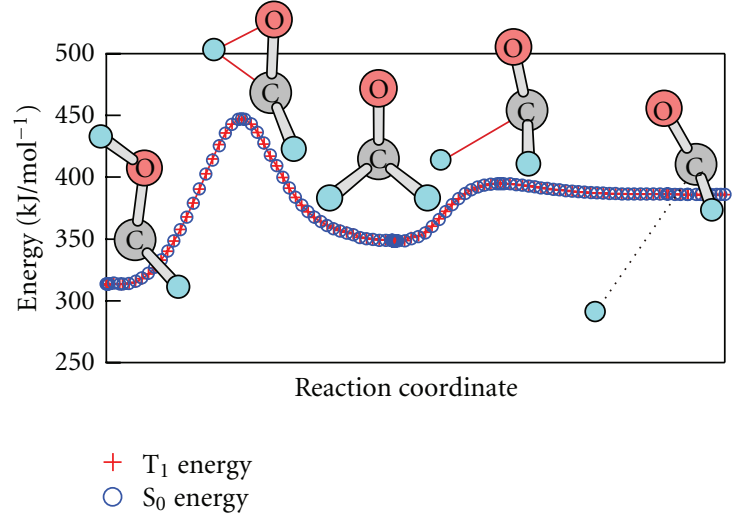

(b)

Figure 4: (a) $\mathrm{A} \mathrm{S}_{0} / \mathrm{T}_{1}$-MEPSX curve for $\mathrm{HCOH} \leftrightarrow \mathrm{H}_{2} \mathrm{CO} \leftrightarrow \mathrm{HCO}+\mathrm{H}$ at the CASPT2 level (see Section 2.4 for details of the CASPT2 calculations) and (b) a $\mathrm{S}_{0} / \mathrm{T}_{1}$-MEPSX curve for the same reaction at the UB3LYP/aug-cc-pVDZ level.

$\mathrm{CH}_{3} \mathrm{CO} \cdots \mathrm{CH}_{3}$ region through only one SPSX structure, that is, it does not enter the potential well of $\left(\mathrm{CH}_{3}\right)_{2} \mathrm{CO}$. In contrast to Figure 4, these intersection spaces lie in a very high-energy region in the potential well of $\left(\mathrm{CH}_{3}\right)_{2} \mathrm{CO}$. Only outside the potential well, the intersection space comes down to a low-energy region. Thus, the $\mathrm{S}_{0} / \mathrm{T}_{1}$ ISC is expected to be much slower in $\left(\mathrm{CH}_{3}\right)_{2} \mathrm{CO}$ than the case of $\mathrm{H}_{2} \mathrm{CO}$, although $\left(\mathrm{CH}_{3}\right)_{2} \mathrm{CO}$ also has a very wide $\mathrm{S}_{0} / \mathrm{T}_{1}$ intersection space.

\section{A Merit of Automated Search}

The most significant advantage of the present approach is that unexpected pathways can be discovered. Geometry optimization has been a very powerful mean to locate exact MSXs and TSs starting from guessed geometries. However, a guess structure leads only to a TS or a MSX anticipated from it. On excited state PESs, molecules frequently take unexpected geometries that are very different from those of stable ground state molecules. Hence, the advantage of the present method without guess is very helpful in analyses of photochemical reactions.

We already reported some unexpected paths discovered by the present recipe. The first is the $\mathrm{S}_{0} / \mathrm{T}_{1}$ ISC path for $\mathrm{H}_{2} \mathrm{CO}$ as discussed above [49]. The second is an $\mathrm{H}$-atom roundtrip path discovered in photolysis of methyl-ethylketone $\mathrm{CH}_{3} \mathrm{C}(\mathrm{O}) \mathrm{C}_{2} \mathrm{H}_{5}$ [138]. In this path, on the $\mathrm{S}_{1}$ PES, an $\mathrm{H}$ atom in the ethylgroup at first transfers to the $\mathrm{O}$ atom to undergo an $\mathrm{S}_{0} / \mathrm{S}_{1}$ IC in a conical intersection of a diradical isomer, and then the $\mathrm{H}$ atom comes back to the original position on the $\mathrm{S}_{0} \mathrm{PES}$, and finally the molecule dissociates into $\mathrm{CH}_{3} \mathrm{CO}+\mathrm{C}_{2} \mathrm{H}_{5}$ or $\mathrm{C}_{2} \mathrm{H}_{5} \mathrm{CO}+\mathrm{CH}_{3}$ on the $\mathrm{S}_{0}$ PES. This path explained an experimental photodissociation quantum yields measurements very well. The third is the discovery for the first time of the excited state roaming pathway, which we found in photolysis of $\mathrm{NO}_{3}[107,108]$. Here, one of the $\mathrm{O}$ atoms in $\mathrm{NO}_{3}$ partially dissociates on the first excited doublet $\left(\mathrm{D}_{1}\right)$ PES and then roams around the $\mathrm{NO}_{2}$ fragment before producing $\mathrm{O}_{2}+\mathrm{NO}$ on either the $\mathrm{D}_{1}$ PES or the ground state $\mathrm{D}_{0}$ PES. This mechanism also explained very well recent experimental results giving two channels, one with hot $\mathrm{O}_{2}$ and the other with cold $\mathrm{O}_{2}[105,106]$. Unexpected nonadiabatic ignition paths of unsaturated hydrocarbons were also discovered by the SMFAFIR approach very recently [50].

\section{Conclusion and Perspective}

We reviewed our recipe to explore multiple PESs systematically by using an automated reaction path search method which has been used for the ground state (smooth) PESs $[49,50]$. In this paper, it was applied together with the GRRM method [43-45] to small carbonyl compounds to study their photodissociation mechanisms. In an application to $\mathrm{H}_{2} \mathrm{CO}$ [49], we discovered a new nonadiabatic $\left(\mathrm{S}_{0} / \mathrm{T}_{1}\right.$ ISC) path to reproduce the ground state species in the potential well of $\mathrm{H}_{2} \mathrm{CO}$. This path was recently confirmed by extensive 3S-TSH simulations using very accurate PESs [117]. For $\left(\mathrm{CH}_{3}\right)_{2} \mathrm{CO}$ [51], many possible nonadiabatic decay paths from the $S_{1}$ PES were systematically located, and new insight into the slow $S_{1} / T_{1}$ ISC and new nonadiabatic paths to the ground state PES were obtained.

Three or more states may couple simultaneously in some reactions. An extension of the present approaches is straightforward since both (1) and (2) are similar to the equation for the diabatic/adiabatic transformation, although we have not yet made systematic tests for such cases.

Dynamic effects may play a significant role in many reactions. Although direct dynamics is very useful in simulations with moderate accuracies [139], it is still too expensive to find all the reaction events of a given system including slow events. There are many powerful approaches applied to ground state PESs to accelerate a dynamics for known mechanisms [140-142]. A prior mechanism search by the present approach followed by such accelerated dynamics may be a solution in the future for theoretical solving complicated reaction mechanisms. The present method can also be connected to the analytical PES fitting approach [143-146] which enabled the recent extensive 3S-TSH simulations of 


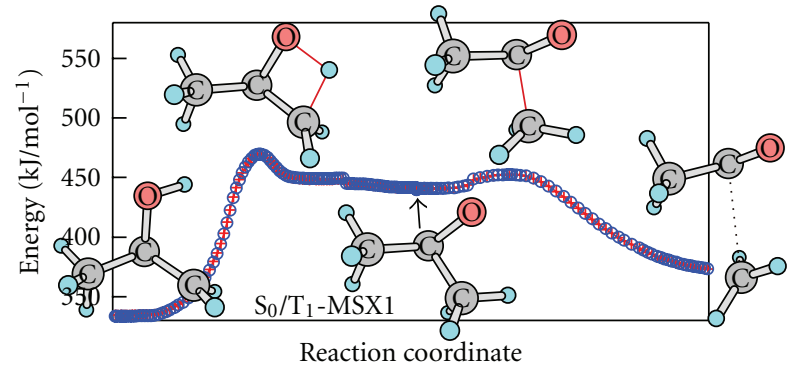

(a)

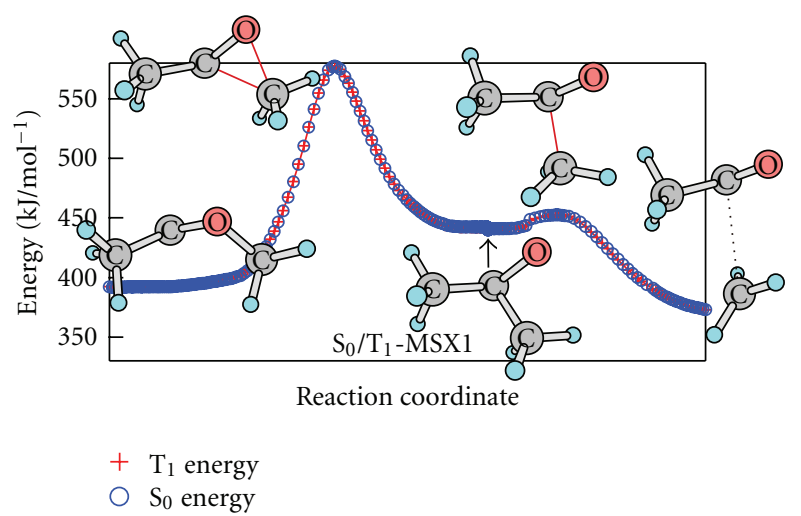

(b)

Figure 5: (a) $\mathrm{A} \mathrm{S}_{0} / \mathrm{T}_{1}$-MEPSX curve for $\mathrm{H}_{2} \mathrm{C}=\mathrm{C}(\mathrm{OH}) \mathrm{CH}_{3} \leftrightarrow\left(\mathrm{CH}_{3}\right)_{2} \mathrm{CO} \leftrightarrow \mathrm{CH}_{3} \mathrm{CO}+\mathrm{CH}_{3}$ and (b) a $\mathrm{S}_{0} / \mathrm{T}_{1}-\mathrm{MEPSX}$ curve for $\mathrm{CH} \mathrm{H}_{3}-\mathrm{CO}-$ $\mathrm{CH}_{3} \leftrightarrow\left(\mathrm{CH}_{3}\right)_{2} \mathrm{CO} \leftrightarrow \mathrm{CH}_{3} \mathrm{CO}+\mathrm{CH}_{3}$, at the UB3LYP/6-31+G* level.

$\mathrm{H}_{2} \mathrm{CO}$ [117]. This approach permits the execution of highly accurate simulations, although applications are limited to small systems including less than 20 atoms. In constructing an analytical PES, prior knowledge about the mechanisms obtained by the present approach will be very useful for effective sampling of the PES data with the least number of ab initio calculations, avoiding exhaustive sampling on a perfect grid covering all configurations. One technical but significant issue in this approach is how to represent the square root topology of conical intersections, and several approaches have been proposed [147-150].

Our particular interest is to apply the present approach to multiple PESs described by combined quantum mechanical and molecular mechanical (QM/MM) calculations [151154]. We have already reported automated reaction path search on the ground state PES of the QM/MM-ONIOM method [155] by combined microiteration [156, 157] and GRRM methods [158], where use of AFIR instead of GRRM has already been possible. This development is expected to greatly expand the applicability of the present approach to large systems.

\section{Acknowledgements}

This work is partly supported by a grant from Japan Science and Technology Agency with a Core Research for Evolutional Science and Technology (CREST) in the area of highperformance computing for multiscale and multiphysics phenomena at Kyoto University as well as a grant from US AFOSR (Grant no. FA9550-10-1-0304) at Emory University.

\section{References}

[1] F. Bernardi, M. Olivucci, and M. A. Robb, "Potential energy surface crossings in organic photochemistry," Chemical Society Reviews, vol. 25, no. 5, pp. 321-328, 1996.

[2] D. R. Yarkony, "Conical intersections: diabolical and often misunderstood," Accounts of Chemical Research, vol. 31, no. 8, pp. 511-518, 1998.
[3] D. Schröder, S. Shaik, and H. Schwarz, "Two-state reactivity as a new concept in organometallic chemistry," Accounts of Chemical Research, vol. 33, no. 3, pp. 139-145, 2000.

[4] A. L. Sobolewski, W. Domcke, C. Dedonder-Lardeux, and C. Jouvet, "Excited-state hydrogen detachment and hydrogen transfer driven by repulsive $1 \pi \sigma^{*}$ states: a new paradigm for nonradiative decay in aromatic biomolecules," Physical Chemistry Chemical Physics, vol. 4, no. 7, pp. 1093-1100, 2002.

[5] R. Poli and J. N. Harvey, "Spin forbidden chemical reactions of transition metal compounds. New ideas and new computational challenges," Chemical Society Reviews, vol. 32, no. 1, pp. 1-8, 2003.

[6] B. G. Levine and T. J. Martínez, "Isomerization through conical intersections," Annual Review of Physical Chemistry, vol. 58, pp. 613-634, 2007.

[7] S. Nanbu, T. Ishida, and H. Nakamura, "Future perspectives of nonadiabatic chemical dynamics," Chemical Science, vol. 1, pp. 663-674, 2010.

[8] N. Koga and K. Morokuma, "Determination of the lowest energy point on the crossing seam between two potential surfaces using the energy gradient," Chemical Physics Letters, vol. 119, no. 5, pp. 371-374, 1985.

[9] M. R. Manaa and D. R. Yarkony, "On the intersection of two potential energy surfaces of the same symmetry. Systematic characterization using a Lagrange multiplier constrained procedure," The Journal of Chemical Physics, vol. 99, no. 7, pp. 5251-5256, 1993.

[10] J. M. Anglada and J. M. Bofill, "A reduced-restrictedquasi-Newton-Raphson method for locating and optimizing energy crossing points between two potential energy surfaces," Journal of Computational Chemistry, vol. 18, no. 8, pp. 992-1003, 1997.

[11] M. J. Bearpark, M. A. Robb, and H. Bernhard Schlegel, "A direct method for the location of the lowest energy point on a potential surface crossing," Chemical Physics Letters, vol. 223, no. 3, pp. 269-274, 1994.

[12] F. Sicilia, L. Blancafort, M. J. Bearpark, and M. A. Robb, “New algorithms for optimizing and linking conical intersection points," Journal of Chemical Theory and Computation, vol. 4, no. 2, pp. 257-266, 2008. 
[13] C. Ciminelli, G. Granucci, and M. Persico, "The photoisomerization mechanism of azobenzene: a semiclassical simulation of nonadiabatic dynamics," Chemistry, vol. 10, no. 9, pp. 2327-2341, 2004.

[14] B. G. Levine, J. D. Coe, and T. J. Martínez, "Optimizing conical intersections without derivative coupling vectors: application to multistate multireference second-order perturbation theory (MS-CASPT2)," Journal of Physical Chemistry B, vol. 112, no. 2, pp. 405-413, 2008.

[15] T. W. Keal, A. Koslowski, and W. Thiel, "Comparison of algorithms for conical intersection optimisation using semiempirical methods," Theoretical Chemistry Accounts, vol. 118, no. 5-6, pp. 837-844, 2007.

[16] S. Maeda, K. Ohno, and K. Morokuma, "Updated branching plane for finding conical intersections without coupling derivative vectors," Journal of Chemical Theory and Computation, vol. 6, no. 5, pp. 1538-1545, 2010.

[17] J. W. McIver Jr. and A. Komornicki, "Structure of transition states in organic reactions. General theory and an application to the cyclobutene-butadiene isomerization using a semiempirical molecular orbital method," Journal of the American Chemical Society, vol. 94, no. 8, pp. 2625-2633, 1972.

[18] A. Komornicki, K. Ishida, K. Morokuma, R. Ditchfield, and M. Conrad, "Efficient determination and characterization of transition states using ab-initio methods," Chemical Physics Letters, vol. 45, no. 3, pp. 595-602, 1977.

[19] H. B. Schlegel, "Optimization of equilibrium geometries and transition structures," Journal of Computational Chemistry, vol. 3, no. 2, pp. 214-218, 1982.

[20] Ö Farkas and H. B. Schlegel, "Methods for optimizing large molecules. II. Quadratic search,” Journal of Chemical Physics, vol. 111, no. 24, pp. 10806-10814, 1999.

[21] C. J. Cerjan and W. H. Miller, "On finding transition states," The Journal of Chemical Physics, vol. 75, no. 6, pp. 2800-2801, 1981.

[22] P. Császár and P. Pulay, "Geometry optimization by direct inversion in the iterative subspace," Journal of Molecular Structure, vol. 114, no. 1-2, pp. 31-34, 1984.

[23] A. Banerjee, N. Adams, J. Simons, and R. Shepard, "Search for stationary points on surfaces," Journal of Physical Chemistry, vol. 89, no. 1, pp. 52-57, 1985.

[24] H. B. Schlegel, "Exploring potential energy surfaces for chemical reactions: an overview of some practical methods," Journal of Computational Chemistry, vol. 24, no. 12, pp. 15141527, 2003.

[25] F. Jensen, Introduction to Computational Chemistry, John Wiley \& Sons, Chichester, UK, 2nd edition, 2007.

[26] H. B. Schlegel, "Geometry optimization," Wiley Interdisciplinary Reviews: Computational Molecular Science, vol. 1, no. 5, pp. 790-809, 2011.

[27] T. A. Halgren and W. N. Lipscomb, “The synchronous-transit method for determining reaction pathways and locating molecular transition states," Chemical Physics Letters, vol. 49, no. 2, pp. 225-232, 1977.

[28] M. J. S. Dewar, E. F. Healy, and J. J. P. Stewart, "Location of transition states in reaction mechanisms," Journal of the Chemical Society, Faraday Transactions 2: Molecular and Chemical Physics, vol. 80, no. 3, pp. 227-233, 1984.

[29] R. Elber and M. Karplus, "A method for determining reaction paths in large molecules: application to myoglobin," Chemical Physics Letters, vol. 139, no. 5, pp. 375-380, 1987.

[30] G. Henkelman, B. P. Uberuaga, and H. Jónsson, “Climbing image nudged elastic band method for finding saddle points and minimum energy paths," Journal of Chemical Physics, vol. 113, no. 22, pp. 9901-9904, 2000.

[31] W. Ren and E. Vanden-Eijnden, "String method for the study of rare events," Physical Review B, vol. 66, no. 5, Article ID 052301, 2002.

[32] B. Peters, A. Heyden, A. T. Bell, and A. Chakraborty, "A growing string method for determining transition states: comparison to the nudged elastic band and string methods," Journal of Chemical Physics, vol. 120, no. 17, pp. 7877-7886, 2004.

[33] S. Maeda and K. Ohno, "A new approach for finding a transition state connecting a reactant and a product without initial guess: applications of the scaled hypersphere search method to isomerization reactions of $\mathrm{HCN},\left(\mathrm{H}_{2} \mathrm{O}\right)_{2}$, and alanine dipeptide," Chemical Physics Letters, vol. 404, no. 1-3, pp. 95-99, 2005.

[34] S. Maeda and K. Ohno, "Conversion pathways between a fullerene and a ring among $\mathrm{C}_{20}$ clusters by a sphere contracting walk method: remarkable difference in local potential energy landscapes around the fullerene and the ring," Journal of Chemical Physics, vol. 124, no. 17, Article ID 174306, 2006.

[35] M. Černohorský, S. Kettou, and J. Koča, "VADER : new software for exploring interconversions on potential energy surfaces," Journal of Chemical Information and Computer Sciences, vol. 39, no. 4, pp. 705-712, 1999.

[36] A. Laio and M. Parrinello, "Escaping free-energy minima," Proceedings of the National Academy of Sciences of the United States of America, vol. 99, no. 20, pp. 12562-12566, 2002.

[37] S. K. Burger and P. W. Ayers, "Dual grid methods for finding the reaction path on reduced potential energy surfaces," Journal of Chemical Theory and Computation, vol. 6, no. 5, pp. 1490-1497, 2010.

[38] J. Q. Sun and K. Ruedenberg, "Gradient extremals and steepest descent lines on potential energy surfaces," The Journal of Chemical Physics, vol. 98, no. 12, pp. 9707-9714, 1993.

[39] K. Bondensgård and F. Jensen, "Gradient extremal bifurcation and turning points: an application to the $\mathrm{H}_{2} \mathrm{CO}$ potential energy surface," Journal of Chemical Physics, vol. 104, no. 20, pp. 8025-8031, 1996.

[40] W. Quapp, M. Hirsch, O. Imig, and D. Heidrich, "Searching for saddle points of potential energy surfaces by following a reduced gradient," Journal of Computational Chemistry, vol. 19, no. 9, pp. 1087-1100, 1998.

[41] K. K. Irikura and R. D. Johnson, "Predicting unexpected chemical reactions by isopotential searching," Journal of Physical Chemistry A, vol. 104, no. 11, pp. 2191-2194, 2000.

[42] E. M. Müller, A. de Meijere, and H. Grubmüller, "Predicting unimolecular chemical reactions: chemical flooding," Journal of Chemical Physics, vol. 116, no. 3, pp. 897-905, 2002.

[43] K. Ohno and S. Maeda, "A scaled hypersphere search method for the topography of reaction pathways on the potential energy surface," Chemical Physics Letters, vol. 384, no. 4-6, pp. 277-282, 2004.

[44] S. Maeda and K. Ohno, "Global mapping of equilibrium and transition structures on potential energy surfaces by the scaled hypersphere search method: applications to ab initio surfaces of formaldehyde and propyne molecules," Journal of Physical Chemistry A, vol. 109, no. 25, pp. 5742-5753, 2005.

[45] K. Ohno and S. Maeda, "Global reaction route mapping on potential energy surfaces of formaldehyde, formic acid, and their metal-substituted analogues," Journal of Physical Chemistry A, vol. 110, no. 28, pp. 8933-8941, 2006. 
[46] S. Maeda and K. Morokuma, "Communications: a systematic method for locating transition structures of $\mathrm{A}+\mathrm{B} \rightarrow \mathrm{X}$ type reactions," Journal of Chemical Physics, vol. 132, no. 24, Article ID 241102, 2010.

[47] S. Maeda, S. Komagawa, M. Uchiyama, and K. Morokuma, "Finding reaction pathways for multicomponent reactions: the passerini reaction is a four-component reaction," Angewandte Chemie, vol. 50, no. 3, pp. 644-649, 2011.

[48] S. Maeda and K. Morokuma, "'Finding reaction pathways of type $\mathrm{A}+\mathrm{B} \rightarrow \mathrm{X}$ : toward systematic prediction of reaction mechanisms," Journal of Chemical Theory and Computation, vol. 7, no. 8, pp. 2335-2345, 2011.

[49] S. Maeda, K. Ohno, and K. Morokuma, "Automated global mapping of minimal energy points on seams of crossing by the anharmonic downward distortion following method: a case study of $\mathrm{H}_{2} \mathrm{CO}$," Journal of Physical Chemistry A, vol. 113, no. 9, pp. 1704-1710, 2009.

[50] S. Maeda, R. Saito, and K. Morokuma, "Finding minimum structures on the seam of crossing in reactions of type A $+\mathrm{B} \rightarrow \mathrm{X}$ : exploration of nonadiabatic ignition pathways of unsaturated hydrocarbons," Journal of Physical Chemistry Letters, vol. 2, no. 8, pp. 852-857, 2011.

[51] S. Maeda, K. Ohno, and K. Morokuma, "A theoretical study on the photodissociation of acetone: insight into the slow intersystem crossing and exploration of nonadiabatic pathways to the ground state," Journal of Physical Chemistry Letters, vol. 1, no. 12, pp. 1841-1845, 2010.

[52] K. Fukui, "A formulation of the reaction coordinate," Journal of Physical Chemistry, vol. 74, no. 23, p. 4161, 1970.

[53] K. Ishida, K. Morokuma, and A. Komornicki, "The intrinsic reaction coordinate. An ab initio calculation for $\mathrm{HNC} \rightarrow$ $\mathrm{HCN}$ and $\mathrm{H}^{-}+\mathrm{CH} 4 \rightarrow \mathrm{CH}_{4}+\mathrm{H}^{-}$," The Journal of Chemical Physics, vol. 66, no. 5, pp. 2153-2156, 1976.

[54] K. Müller and L. D. Brown, "Location of saddle points and minimum energy paths by a constrained simplex optimization procedure," Theoretica Chimica Acta, vol. 53, no. 1, pp. 75-93, 1979.

[55] M. Page and J. W. McIver Jr., "On evaluating the reaction path Hamiltonian," The Journal of Chemical Physics, vol. 88, no. 2, pp. 922-935, 1988.

[56] C. Gonzalez and H. Bernhard Schlegel, "An improved algorithm for reaction path following," The Journal of Chemical Physics, vol. 90, no. 4, pp. 2154-2161, 1989.

[57] H. P. Hratchian and H. B. Schlegel, "Using Hessian updating to increase the efficiency of a Hessian based predictorcorrector reaction path following method," Journal of Chemical Theory and Computation, vol. 1, no. 1, pp. 61-69, 2005.

[58] S. Maeda and K. Ohno, "Structures of water octamers $\left(\mathrm{H}_{2} \mathrm{O}\right)_{8}$ : exploration on ab initio potential energy surfaces by the scaled hypersphere search method," Journal of Physical Chemistry A, vol. 111, no. 20, pp. 4527-4534, 2007.

[59] H.-J. Werner, P. J. Knowles, F. R. Manby et al., MOLPRO, version 2006.1, a package of ab initio programs, http://www.molpro.net .

[60] S. Maeda, Y. Osada, K. Morokuma, and K. Ohno, GRRM11, http://kmweb.fukui.kyoto-u.ac.jp/ smaeda/GRRM_PR000 .html.

[61] W. M. Gelbart, M. L. Elert, and D. F. Heller, "Photodissociation of the formaldehyde molecule: does it or doesn't it?" Chemical Reviews, vol. 80, no. 5, pp. 403-416, 1980.

[62] C. B. Moore and J. C. Weisshaar, "Formaldehyde photochemistry," Annual Review of Physical Chemistry, vol. 34, pp. 525$555,1983$.
[63] D. J. Clouthier and D. A. Ramsay, "The spectroscopy of formaldehyde and thioformaldehyde," Annual Review of Physical Chemistry, vol. 34, pp. 31-58, 1983.

[64] W. H. Green Jr., C. B. Moore, and W. F. Polik, "Transition states and rate constants for unimolecular reactions," Annual Review of Physical Chemistry, vol. 43, no. 1, pp. 591-626, 1992.

[65] C. B. Moore, "A spectroscopist's view of energy states, energy transfers, and chemical reactions," Annual Review of Physical Chemistry, vol. 58, pp. 1-33, 2007.

[66] D. M. Hayes and K. Morokuma, "Theoretical studies of carbonyl photochemistry. I. ab initio potential energy surfaces for the photodissociation $\mathrm{H}_{2} \mathrm{CO}^{*} \rightarrow \mathrm{H}+\mathrm{HCO}$," Chemical Physics Letters, vol. 12, no. 4, pp. 539-543, 1972.

[67] R. L. Jaffe, D. M. Hayes, and K. Morokuma, "Photodissociation of formaldehyde-4: potential energy surfaces for $\mathrm{H}_{2} \mathrm{CO}^{*} \rightarrow \mathrm{H}_{2}+\mathrm{CO}$," The Journal of Chemical Physics, vol. 60, no. 12, pp. 5108-5109, 1974.

[68] J. A. Hernandez and R. Carbo, "Theoretical-study of formaldehyde photodissociation," Journal de Chimie Physique et de Physico-Chimie Biologique, vol. 72, no. 9, pp. 959-960, 1975.

[69] R. L. Jaffe and K. Morokuma, "MCSCF potential energy surface for photodissociation of formaldehyde," The Journal of Chemical Physics, vol. 64, no. 12, pp. 4881-4886, 1976.

[70] J. D. Goddard and H. F. Schaefer, "The photodissociation of formaldehyde: potential energy surface features," The Journal of Chemical Physics, vol. 70, no. 11, pp. 5117-5134, 1979.

[71] N. C. Handy and S. Carter, "An improved potential surface for formaldehyde," Chemical Physics Letters, vol. 79, no. 1, pp. 118-124, 1981.

[72] R. Schinke, "Rotational state distributions of $\mathrm{H}_{2}$ and $\mathrm{CO}$ following the photofragmentation of formaldehyde," The Journal of Chemical Physics, vol. 84, no. 3, pp. 1487-1491, 1986.

[73] G. E. Scuseria and H. F. Schaefer, "The photodissociation of formaldehyde: a coupled cluster study including connected triple excitations of the transition state barrier height for $\mathrm{H}_{2} \mathrm{CO} \rightarrow \mathrm{H}_{2}+\mathrm{CO}$," The Journal of Chemical Physics, vol. 90, no. 7, pp. 3629-3636, 1989.

[74] Y. T. Chang, C. Minichino, and W. H. Miller, "Classical trajectory studies of the molecular dissociation dynamics of formaldehyde: $\mathrm{H}_{2} \mathrm{CO} \rightarrow \mathrm{H}_{2}+\mathrm{CO}$," The Journal of Chemical Physics, vol. 96, no. 6, pp. 4341-4355, 1992.

[75] L. Deng, T. Ziegler, and L. Fan, "A combined density functional and intrinsic reaction coordinate study on the ground state energy surface of $\mathrm{H}_{2} \mathrm{CO}$," The Journal of Chemical Physics, vol. 99, no. 5, pp. 3823-3835, 1993.

[76] W. Chen, W. L. Hase, and H. B. Schlegel, "Ab initio classical trajectory study of $\mathrm{H}_{2} \mathrm{CO} \rightarrow \mathrm{H}_{2}+\mathrm{CO}$ dissociation," Chemical Physics Letters, vol. 228, no. 4-5, pp. 436-442, 1994.

[77] G. H. Peslherbe and W. L. Hase, "Semiempirical MNDO, AM1, and PM3 direct dynamics trajectory studies of formaldehyde unimolecular dissociation," Journal of Chemical Physics, vol. 104, no. 20, pp. 7882-7894, 1996.

[78] H. Nakano, K. Nakayama, K. Hirao, and M. Dupuis, "Transition state barrier height for the reaction $\mathrm{H}_{2} \mathrm{CO} \rightarrow$ $\mathrm{H}_{2}+\mathrm{CO}$ studied by multireference Møller-Plesset perturbation theory," Journal of Chemical Physics, vol. 106, no. 12, pp. 4912-4917, 1997.

[79] F. Jensen, "Stationary points on the $\mathrm{H}_{2} \mathrm{CO}$ potential energy surface: dependence on theoretical level," Theoretical Chemistry Accounts, vol. 99, no. 5, pp. 295-300, 1998.

[80] D. Feller, M. Dupuis, and B. C. Garrett, "Barrier for the $\mathrm{H}_{2} \mathrm{CO} \rightarrow \mathrm{H}_{2}+\mathrm{CO}$ reaction: a discrepancy between high-level 
electronic structure calculations and experiment," Journal of Chemical Physics, vol. 113, no. 1, pp. 218-226, 2000.

[81] X. Li, J. M. Millam, and H. B. Schlegel, "Ab initio molecular dynamics studies of the photodissociation of formaldehyde, $\mathrm{H}_{2} \mathrm{CO} \rightarrow \mathrm{H}_{2}+\mathrm{CO}$ : direct classical trajectory calculations by MP2 and density functional theory," Journal of Chemical Physics, vol. 113, no. 22, pp. 10062-10067, 2000.

[82] H. B. Schlegel, S. S. Iyengar, X. Li et al., "Ab initio molecular dynamics: propagating the density matrix with Gaussian orbitals. III. Comparison with Born-Oppenheimer dynamics," Journal of Chemical Physics, vol. 117, no. 19, pp. 86948704, 2002.

[83] T. Yonehara and S. Kato, "Role of isomerization channel in unimolecular dissociation reaction $\mathrm{H}_{2} \mathrm{CO} \rightarrow \mathrm{H}_{2}+\mathrm{CO}: \mathrm{Ab}$ initio global potential energy surface and classical trajectory analysis," Journal of Chemical Physics, vol. 117, no. 24, pp. 11131-11138, 2003.

[84] X. Zhang, S. Zou, L. B. Harding, and J. M. Bowman, "A global $\mathrm{ab}$ initio potential energy surface for formaldehyde," Journal of Physical Chemistry A, vol. 108, no. 41, pp. 8980-8986, 2004.

[85] X. Zhang, J. L. Rheinecker, and J. M. Bowman, "Quasiclassical trajectory study of formaldehyde unimolecular dissociation: $\mathrm{H}_{2} \mathrm{CO} \rightarrow \mathrm{H}_{2}+\mathrm{CO}, \mathrm{H}+\mathrm{HCO}$," Journal of Chemical Physics, vol. 122, no. 11, Article ID 114313, 8 pages, 2005.

[86] T. Yonehara and S. Kato, "Quantum dynamics study on multichannel dissociation and isomerization reactions of formaldehyde," Journal of Chemical Physics, vol. 125, no. 8, Article ID 084307, 2006.

[87] J. M. Bowman and X. Zhang, "New insights on reaction dynamics from formaldehyde photodissociation," Physical Chemistry Chemical Physics, vol. 8, no. 3, pp. 321-332, 2006.

[88] L. B. Harding, S. J. Klippenstein, and A. W. Jasper, "Ab initio methods for reactive potential surfaces," Physical Chemistry Chemical Physics, vol. 9, no. 31, pp. 4055-4070, 2007.

[89] S. Maeda and K. Ohno, "A new global reaction route map on the potential energy surface of $\mathrm{H}_{2} \mathrm{CO}$ with unrestricted level," Chemical Physics Letters, vol. 460, no. 1-3, pp. 55-58, 2008.

[90] Y. Yamaguchi, S. S. Wesolowski, T. J. Van Huis, and H. F. Schaefer, "The unimolecular dissociation of $\mathrm{H}_{2} \mathrm{CO}$ on the lowest triplet potential-energy surface," Journal of Chemical Physics, vol. 108, no. 13, pp. 5281-5288, 1998.

[91] H. M. Yin, S. H. Kable, X. Zhang, and J. M. Bowman, "Signatures of $\mathrm{H}_{2} \mathrm{CO}$ photodissociation from two electronic states," Science, vol. 311, no. 5766, pp. 1443-1446, 2006.

[92] K. K. Baeck, "The analytic gradient for the equation-ofmotion coupled-cluster energy with a reduced molecular orbital space: an application for the first excited state of formaldehyde," Journal of Chemical Physics, vol. 112, no. 1, pp. 1-4, 2000.

[93] J. B. Simonsen, N. Rusteika, M. S. Johnson, and T. I. Sølling, "Atmospheric photochemical loss of $\mathrm{H}$ and $\mathrm{H}_{2}$ from formaldehyde: the relevance of ultrafast processes," Physical Chemistry Chemical Physics, vol. 10, no. 5, pp. 674-680, 2008.

[94] R. D. Van Zee, M. F. Foltz, and C. B. Moore, "Evidence for a second molecular channel in the fragmentation of formaldehyde," Journal of Chemical Physics, vol. 99, no. 3, pp. 1664-1673, 1993.

[95] D. Townsend, S. A. Lahankar, S. K. Lee et al., "The roaming atom: straying from the reaction path in formaldehyde decomposition," Science, vol. 306, no. 5699, pp. 1158-1161, 2004.
[96] A. G. Suits, "Roaming atoms and radicals: a new mechanism in molecular dissociation," Accounts of Chemical Research, vol. 41, no. 7, pp. 873-881, 2008.

[97] N. Herath and A. G. Suits, "Roaming radical reactions," Journal of Physical Chemistry Letters, vol. 2, no. 6, pp. 642647, 2011.

[98] J. M. Bowman and B. C. Shepler, "Roaming radicals," Annual Review of Physical Chemistry, vol. 62, pp. 531-553, 2011.

[99] P. L. Houston and S. H. Kable, "Photodissociation of acetaldehyde as a second example of the roaming mechanism," Proceedings of the National Academy of Sciences of the United States of America, vol. 103, no. 44, pp. 16079-16082, 2006.

[100] B. C. Shepler, B. J. Braams, and J. M. Bowman, "Quasiclassical trajectory calculations of acetaldehyde dissociation on a global potential energy surface indicate significant nontransition state dynamics," Journal of Physical Chemistry A, vol. 111, no. 34, pp. 8282-8285, 2007.

[101] B. R. Heazlewood, M. J. T. Jordan, S. H. Kable et al., "Roaming is the dominant mechanism for molecular products in acetaldehyde photodissociation," Proceedings of the National Academy of Sciences of the United States of America, vol. 105, no. 35, pp. 12719-12724, 2008.

[102] V. Goncharov, N. Herath, and A. G. Suits, "Roaming dynamics in acetone dissociation," Journal of Physical Chemistry A, vol. 112, no. 39, pp. 9423-9428, 2008.

[103] C. Chen, B. Braams, D. Y. Lee, J. M. Bowman, P. L. Houston, and D. Stranges, "Evidence for vinylidene production in the photodissociation of the allyl radical," Journal of Physical Chemistry Letters, vol. 1, no. 12, pp. 1875-1880, 2010.

[104] E. Kamarchik, L. Koziol, H. Reisler, J. M. Bowman, and A. I. Krylov, "Roaming pathway leading to unexpected water + vinyl products in $\mathrm{C}_{2} \mathrm{H}_{4} \mathrm{OH}$ dissociation," Journal of Physical Chemistry Letters, vol. 1, no. 20, pp. 3058-3065, 2010.

[105] M. P. Grubb, M. L. Warter, A. G. Suits, and S. W. North, "Evidence of roaming dynamics and multiple channels for molecular elimination in $\mathrm{NO}_{3}$ photolysis," The Journal of Physical Chemistry Letters, vol. 1, pp. 2455-2458, 2010.

[106] M. P. Grubb, M. L. Warter, K. M. Johnson, and S. W. North, "Ion imaging study of $\mathrm{NO}_{3}$ radical photodissociation dynamics: characterization of multiple reaction pathways," Journal of Physical Chemistry, vol. 115, no. 15, pp. 3218-3226, 2011.

[107] H. Xiao, S. Maeda, and K. Morokuma, "Excited-state roaming dynamics in photolysis of a nitrate radical," Journal of Physical Chemistry Letters, vol. 2, no. 9, pp. 934-938, 2011.

[108] S. W. North, "Roaming in the dark," Nature Chemistry, vol. 3, no. 7, pp. 504-505, 2011.

[109] A. Fernández-Ramos, J. A. Miller, S. J. Klippenstein, and D. G. Truhlar, "Modeling the kinetics of bimolecular reactions," Chemical Reviews, vol. 106, no. 11, pp. 4518-4584, 2006.

[110] L. B. Harding and S. J. Klippenstein, "Roaming radical pathways for the decomposition of alkanes," Journal of Physical Chemistry Letters, vol. 1, no. 20, pp. 3016-3020, 2010.

[111] P. Zhang, Applications of electronic structure theory in the study of molecular processes, Ph.D. thesis, Emory University, 2005.

[112] B. C. Shepler, E. Epifanovsky, P. Zhang, J. M. Bowman, A. I. Krylov, and K. Morokuma, "Photodissociation dynamics of formaldehyde initiated at the $\mathrm{T}_{1} / \mathrm{S}_{0}$ minimum energy crossing configurations," Journal of Physical Chemistry A, vol. 112, no. 51, pp. 13267-13270, 2008.

[113] M. Araujo, B. Lasorne, M. J. Bearpark, and M. A. Robb, “The photochemistry of formaldehyde: internal conversion and 
molecular dissociation in a single step?" Journal of Physical Chemistry A, vol. 112, no. 33, pp. 7489-7491, 2008.

[114] P. Zhang, S. Maeda, K. Morokuma, and B. J. Braams, "Photochemical reactions of the low-lying excited states of formaldehyde: $T_{1} / S_{0}$ intersystem crossings, characteristics of the $S_{1}$ and $T_{1}$ potential energy surfaces, and a global $T_{1}$ potential energy surface," Journal of Chemical Physics, vol. 130, no. 11, Article ID 114304, 2009.

[115] M. Araújo, B. Lasorne, A. L. Magalhães, G. A. Worth, M. J. Bearpark, and M. A. Robb, "The molecular dissociation of formaldehyde at medium photoexcitation energies: a quantum chemistry and direct quantum dynamics study," Journal of Chemical Physics, vol. 131, no. 14, Article ID 144301, 2009.

[116] M. Arauéjo, B. Lasorne, A. L. Magalhaes, M. J. Bearpark, and M. A. Robb, "Controlling product selection in the photodissociation of formaldehyde: direct quantum dynamics from the $\mathrm{S}_{1}$ barrier," Journal of Physical Chemistry A, vol. 114, no. 45, pp. 12016-12020, 2010.

[117] B. Fu, B. C. Shepler, and J. M. Bowman, "hree-state trajectory surface hopping studies of the photodissociation dynamics of formaldehyde on ab initio potential energy surfaces," Journal of the American Chemical Society, vol. 133, no. 20, pp. 79577968, 2011.

[118] Y. Haas, "Photochemical $\alpha$-cleavage of ketones: revisiting acetone," Photochemical and Photobiological Sciences, vol. 3, no. 1, pp. 6-16, 2004.

[119] R. A. Copeland and D. R. Crosley, "Radiative, collisional and dissociative processes in triplet acetone," Chemical Physics Letters, vol. 115, no. 4-5, pp. 362-368, 1985.

[120] H. Zuckermann, B. Schmitz, and Y. Haas, "Dissociation energy of an isolated triplet acetone molecule," Journal of Physical Chemistry, vol. 92, no. 17, pp. 4835-4837, 1988.

[121] S. W. North, D. A. Blank, J. Daniel Gezelter, C. A. Longfellow, and Y. T. Lee, "Evidence for stepwise dissociation dynamics in acetone at 248 and $193 \mathrm{~nm}$," The Journal of Chemical Physics, vol. 102, no. 11, pp. 4447-4460, 1995.

[122] D. Liu, W. H. Fang, and X. Y. Fu, "An ab initio study on photodissociation of acetone," Chemical Physics Letters, vol. 325 , no. 1-3, pp. 86-92, 2000.

[123] E. W. G. Diau, G. Kötting, and A. H. Zewail, "Femtochemistry of norrish type-1 reactions. I. Experimental and theoretical studies of acetone and related ketones on the $\mathrm{s} 1$ surface," ChemPhysChem, vol. 2, no. 5, pp. 273-293, 2001.

[124] E. W. G. Diau, C. Kötting, T. I. Sølling, and A. H. Zewail, "Femtochemistry of Norrish type-I reactions. III. Highly excited ketones-theoretical," ChemPhysChem, vol. 3, no. 1, pp. 57-78, 2002.

[125] T. I. Sølling, E. W. G. Diau, C. Kötting, S. de Feyter, and A. H. Zewail, "Femtochemistry of Norrish type-I reactions. IV. Highly excited ketones-experimental," ChemPhysChem, vol. 3, no. 1, pp. 79-97, 2002.

[126] W. K. Chen, J. W. Ho, and P. Y. Cheng, "Ultrafast photodissociation dynamics of the acetone 3s Rydberg state at $195 \mathrm{~nm}$ : a new mechanism," Chemical Physics Letters, vol. 380, no. 3-4, pp. 411-418, 2003.

[127] W. K. Chen, J. W. Ho, and P. Y. Cheng, "Ultrafast photodissociation dynamics of acetone at $195 \mathrm{~nm}$. I. Initial-state, intermediate, and product temporal evolutions by femtosecond mass-selected multiphoton ionization spectroscopy," Journal of Physical Chemistry A, vol. 109, no. 31, pp. 6805-6817, 2005.

[128] W. K. Chen and P. Y. Cheng, "Ultrafast photodissociation dynamics of acetone at $195 \mathrm{~nm}$ : II. Unraveling complex three-body dissociation dynamics by femtosecond timeresolved photofragment translational spectroscopy," Journal of Physical Chemistry A, vol. 109, no. 31, pp. 6818-6829, 2005.

[129] H. Somnitz, M. Fida, T. Ufer, and R. Zellner, "Pressure dependence for the $\mathrm{CO}$ quantum yield in the photolysis of acetone at $248 \mathrm{~nm}$ : a combined experimental and theoretical study," Physical Chemistry Chemical Physics, vol. 7, no. 18, pp. 3342-3352, 2005.

[130] V. Khamaganov, R. Karunanandan, A. Rodriguez, and J. N. Crowley, "Photolysis of $\mathrm{CH}_{3} \mathrm{C}(\mathrm{O}) \mathrm{CH}_{3}(248 \mathrm{~nm}, 266 \mathrm{~nm})$, $\mathrm{CH}_{3} \mathrm{C}(\mathrm{O}) \mathrm{C}_{2} \mathrm{H}_{5}(248 \mathrm{~nm})$ and $\mathrm{CH}_{3} \mathrm{C}(\mathrm{O}) \mathrm{Br}(248 \mathrm{~nm})$ : pressure dependent quantum yields of $\mathrm{CH}_{3}$ formation," Physical Chemistry Chemical Physics, vol. 9, no. 31, pp. 4098-4113, 2007.

[131] R. Nádasdi, G. Kovács, I. Szilágyi et al., "Exciplex laser photolysis study of acetone with relevance to tropospheric chemistry," Chemical Physics Letters, vol. 440, no. 1-3, pp. 3135, 2007.

[132] I. Antol, M. Eckert-Maksić, M. Ončák, P. Slavíček, and H. Lischka, "Photodissociation pathways of acetone upon excitation into the 3s Rydberg state: adiabatic versus diabatic mechanism," Collection of Czechoslovak Chemical Communications, vol. 73, no. 11, pp. 1475-1494, 2008.

[133] H. Somnitz, T. Ufer, and R. Zellner, "Acetone photolysis at $248 \mathrm{~nm}$ revisited: pressure dependence of the $\mathrm{CO}$ and $\mathrm{CO}_{2}$ quantum yields," Physical Chemistry Chemical Physics, vol. 11, no. 38, pp. 8522-8531, 2009.

[134] T. Shibata and T. Suzuki, "Photofragment ion imaging with femtosecond laser pulses," Chemical Physics Letters, vol. 262, no. 1-2, pp. 115-119, 1996.

[135] N. Rusteika, K. B. Møller, and T. I. Sølling, "New insights on the photodynamics of acetone excited with 253-288 nm femtosecond pulses," Chemical Physics Letters, vol. 461, no. 4-6, pp. 193-197, 2008.

[136] R. Y. Brogaard, T. I. Sølling, and K. B. Møller, "Initial dynamics of the Norrish Type I reaction in acetone: probing wave packet motion," Journal of Physical Chemistry A, vol. 115, no. 15, pp. 556-561, 2011.

[137] M. J. Frisch, G. W. Trucks, H. B. Schlegel et al., "Gaussian 09 Revision A.2," Wallingford CT, 2009.

[138] R. Nádasdi, G. L. Zügner, M. Farkas, S. Dõbé, S. Maeda, and K. Morokuma, "Photochemistry of methyl ethyl ketone: quantum yields and $\mathrm{S}_{1} / \mathrm{S}_{0}$-diradical mechanism of photodissociation," ChemPhysChem, vol. 11, no. 18, pp. 3883-3895, 2010.

[139] B. Lasorne, G. A. Worth, and M. A. Robb, "Excited-state dynamics," Wiley Interdisciplinary Reviews: Computational Molecular Science, vol. 1, no. 3, pp. 460-475, 2011.

[140] J. Kästner, "Umbrella sampling," Wiley Interdisciplinary Reviews: Computational Molecular Science, vol. 1, no. 6, pp. 932-942, 2011.

[141] H. Hu and W. Yang, "Free energies of chemical reactions in solution and in enzymes with ab initio quantum mechanics/molecular mechanics methods," Annual Review of Physical Chemistry, vol. 59, pp. 573-601, 2008.

[142] A. Barducci, M. Bonomi, and M. Parrinello, "Metadynamics," Wiley Interdisciplinary Reviews: Computational Molecular Science, vol. 1, no. 5, pp. 826-843, 2011.

[143] G. C. Schatz, "The analytical representation of electronic potential-energy surfaces," Reviews of Modern Physics, vol. 61, no. 3, pp. 669-688, 1989.

[144] M. A. Collins, "Molecular potential-energy surfaces for chemical reaction dynamics," Theoretical Chemistry Accounts, vol. 108, no. 6, pp. 313-324, 2002. 
[145] J. M. Bowman, B. J. Braams, S. Carter et al., "Ab-initiobased potential energy surfaces for complex molecules and molecular complexes," Journal of Physical Chemistry Letters, vol. 1, no. 12, pp. 1866-1874, 2010.

[146] J. M. Bowman, G. Czakó, and B. Fu, "High-dimensional ab initio potential energy surfaces for reaction dynamics calculations," Physical Chemistry Chemical Physics, vol. 13, no. 18, pp. 8094-8111, 2011.

[147] C. R. Evenhuis, X. Lin, D. H. Zhang, D. Yarkony, and M. A. Collins, "Interpolation of diabatic potential-energy surfaces: quantum dynamics on ab initio surfaces," Journal of Chemical Physics, vol. 123, no. 13, Article ID 134110, 12 pages, 2005.

[148] Z. H. Li, R. Valero, and D. G. Truhlar, "Improved direct diabatization and coupled potential energy surfaces for the photodissociation of ammonia," Theoretical Chemistry Accounts, vol. 118, no. 1, pp. 9-24, 2007.

[149] Z. Wang, I. S. K. Kerkines, K. Morokuma, and P. Zhang, "Analytical potential energy surfaces for $\mathrm{N}_{3}$ low-lying doublet states," Journal of Chemical Physics, vol. 130, no. 4, Article ID 044313, 2009.

[150] X. Zhu and D. R. Yarkony, "On the representation of coupled adiabatic potential energy surfaces using quasidiabatic Hamiltonians: description of accidental seams of conical intersection," Molecular Physics, vol. 108, no. 19-20, pp. 2611-2619, 2010.

[151] A. Warshel and M. Levitt, "Theoretical studies of enzymatic reactions: dielectric, electrostatic and steric stabilization of the carbonium ion in the reaction of lysozyme," Journal of Molecular Biology, vol. 103, no. 2, pp. 227-249, 1976.

[152] U. C. Singh and P. A. Kollman, "A combined ab initio quantum mechanical and molecular mechanical method for carrying out simulations on complex molecular systems: applications to the $\mathrm{CH}_{3} \mathrm{Cl}+\mathrm{Cl}^{-}$exchange reaction and gas phase protonation of polyethers," Journal of Computational Chemistry, vol. 7, no. 6, pp. 718-730, 1986.

[153] M. J. Field, P. A. Bash, and M. Karplus, "A combined quantum mechanical and molecular mechanical potential for molecular dynamics simulations," Journal of Computational Chemistry, vol. 11, no. 6, pp. 700-733, 1990.

[154] F. Maseras and K. Morokuma, "IMOMM-a new integrated ab-initio plus molecular mechanics geometry optimization scheme of equilibrium structures and transition-states," Journal of Computational Chemistry, vol. 16, no. 9, pp. 11701179, 1995.

[155] M. Svensson, S. Humbel, R. D. J. Froese, T. Matsubara, S. Sieber, and K. Morokuma, "ONIOM: a multilayered integrated $\mathrm{MO}+\mathrm{MM}$ method for geometry optimizations and single point energy predictions. A test for Diels-Alder reactions and $\mathrm{Pt}\left(\mathrm{P}(t-\mathrm{Bu})_{3}\right)_{2}+\mathrm{H}_{2}$ oxidative addition," Journal of Physical Chemistry, vol. 100, no. 50, pp. 19357-19363, 1996.

[156] T. Vreven, K. Morokuma, Ö Farkas, H. B. Schlegel, and M. J. Frisch, "Geometry optimization with QM/MM, ONIOM, and other combined methods. I. Microiterations and constraints," Journal of Computational Chemistry, vol. 24, no. 6, pp. 760-769, 2003.

[157] T. Vreven, M. J. Frisch, K. N. Kudin, H. B. Schlegel, and K. Morokuma, "Geometry optimization with QM/MM methods II: explicit quadratic coupling," Molecular Physics, vol. 104, pp. 701-714, 2006.

[158] S. Maeda, K. Ohno, and K. Morokuma, "An automated and systematic transition structure explorer in large flexible molecular systems based on combined global reaction route mapping and microiteration methods," Journal of Chemical Theory and Computation, vol. 5, no. 10, pp. 2734-2743, 2009. 


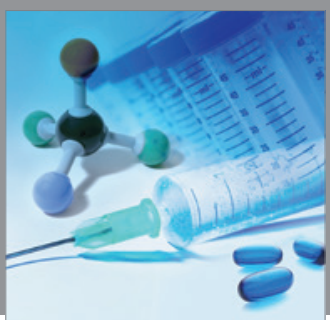

International Journal of

Medicinal Chemistry

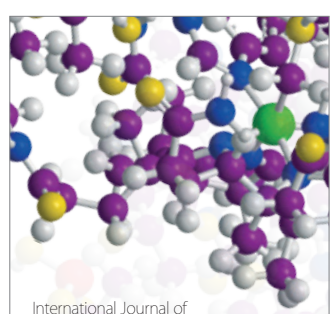

Carbohydrate Chemistry

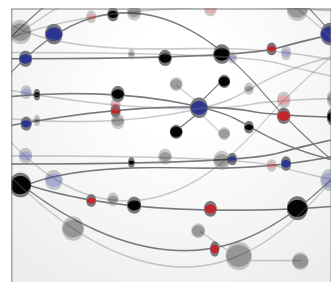

The Scientific World Journal
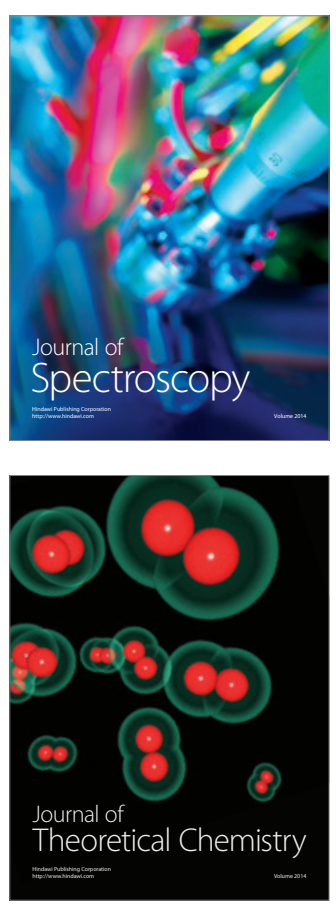
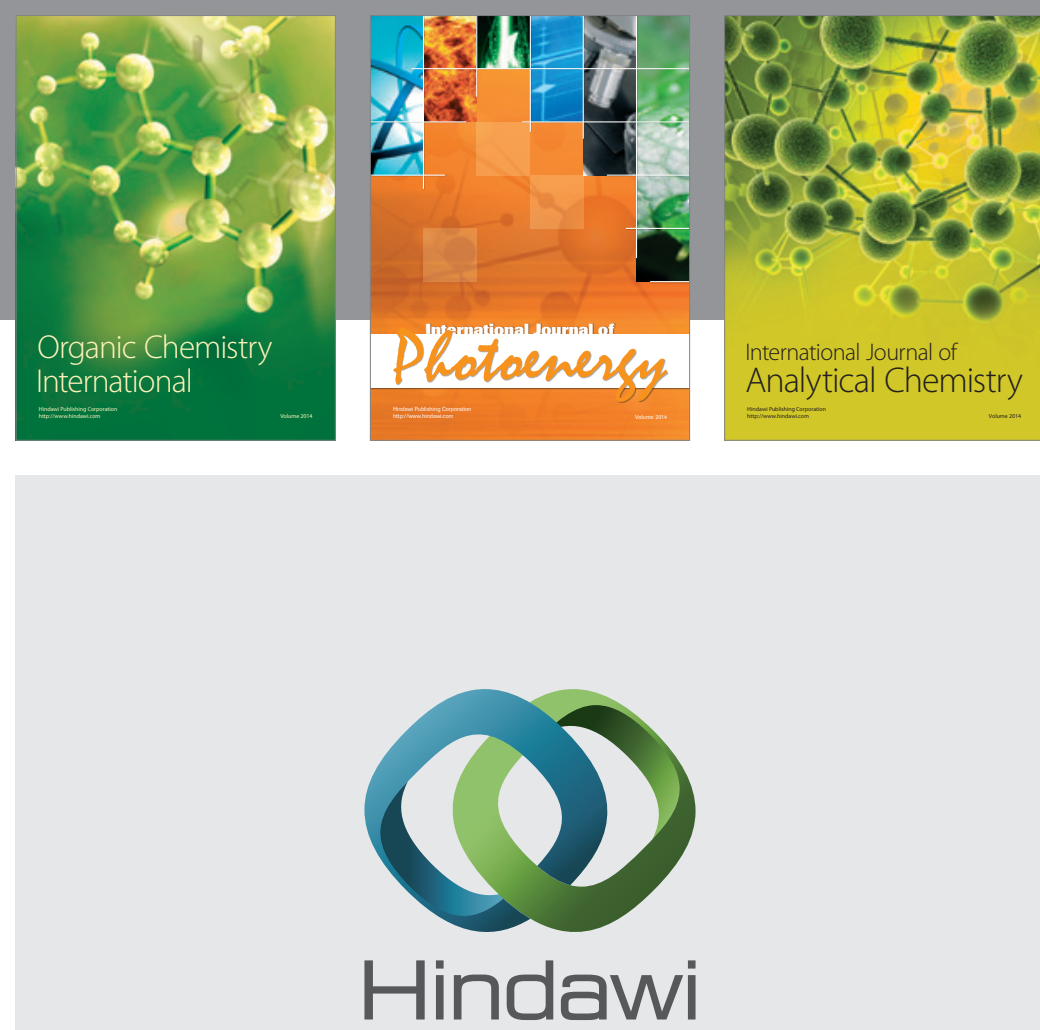

Submit your manuscripts at

http://www.hindawi.com
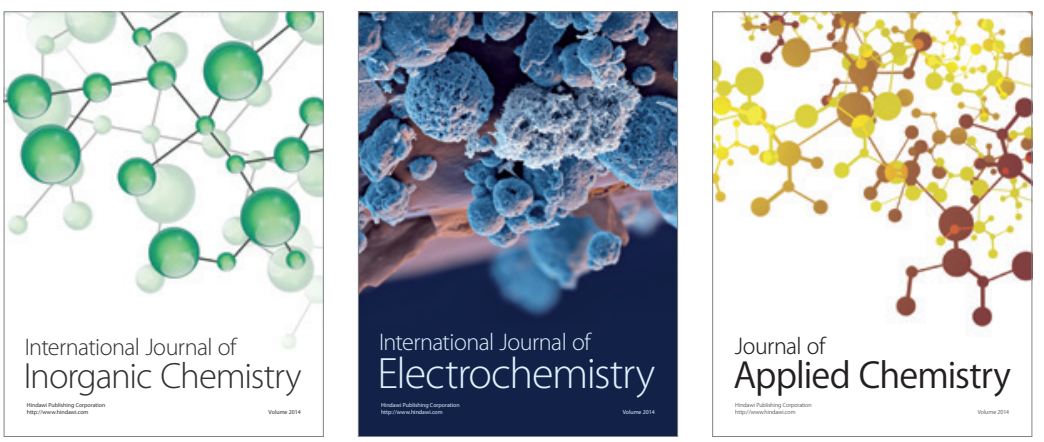

Journal of

Applied Chemistry
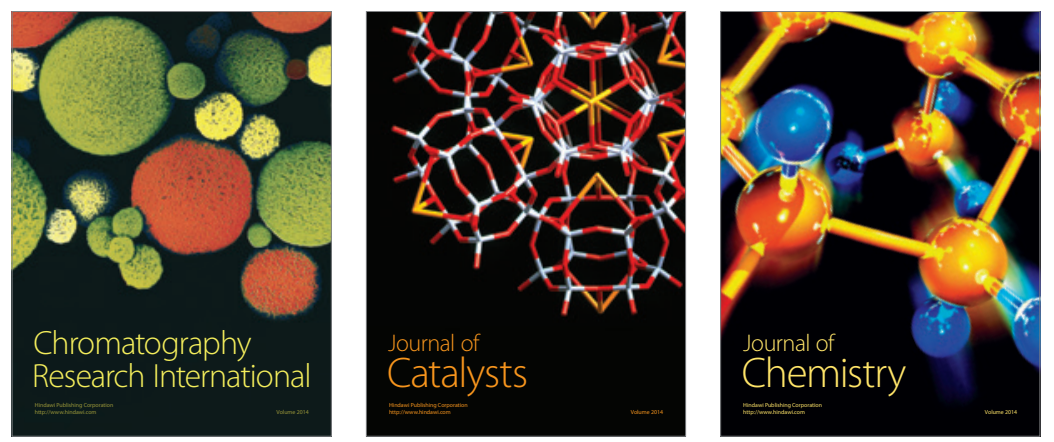
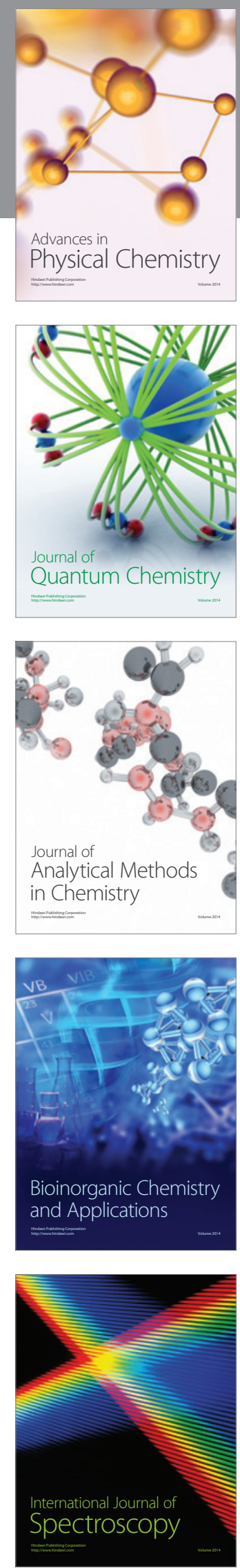